\title{
DESIGN REPORT: SCDAP/RELAP5 REFLOOD OXIDATION MODEL
}

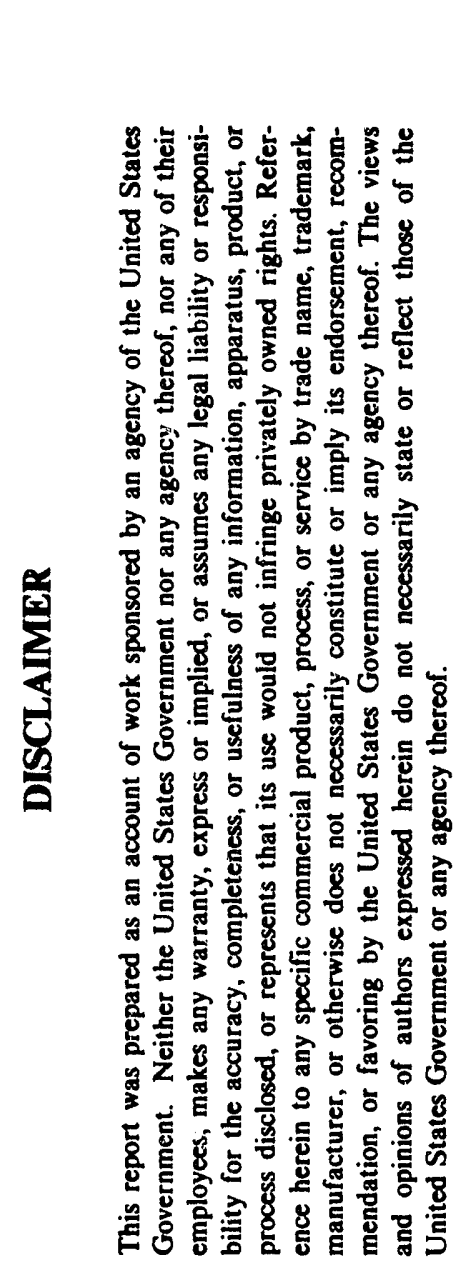

\author{
E. W. Coryell \\ S. A. Chavez \\ K. L. Davis \\ M. H. Mortensen \\ Published October 1992 \\ EG\&G Idaho, Inc. \\ Idaho National Engineering Laboratory \\ Idaho Falls, ID 83415 \\ Prepared for the \\ Division of Safety Research \\ Office of Nuclear Regulatory Research \\ U.S. Nuclear Regulatory Commission \\ Washington, D.C. 20555 \\ Under DOE Idaho Field Office \\ Contract No. DE-AC07-76IDO1570
}

FIN A6889 


\section{ABSTRACT}

Current SCDAP/RELAP5 oxidation models have proven to underpredict oxidation, and therefore hydrogen production, when modeling reflocd during in-pile tests. As an example, while OECD LOFT Experiment LP-FP-2 shows significant increases in temperature and pressure during reflood due to increased oxidation, only minimal additional oxidation is currently predicted with SCDAP/RELAP5. Since SCDAP/RELAP5 predicts a steam rich environment during reflood, the parameter limiting oxidation must be the availability of zircaloy. Two phenomena, not currently modeled, may provide the necessary unoxidized zircaloy during reflood: (1) localized steam starvation prior to reflood, caused by debris blockage or hydrogen generation, or (2) shattering of oxidized cladding during reflood. The objective of this design report is to develop new models to accurately predict zircaloy cladding oxidation during the temperature transients prior to and during reflood. Evidence compiled from postirradiation examination (PIE) of fuel bundles subjected to severe accident conditions from several in-pile tests is used to identify mechanisms for additional cladding oxidation during reflood and to develop specific criteria to determine when these mechanisms are applicable.

FIN No. A6889 -- SCDAP/RELAP5/MOD3 Maintenance 


\section{Table of Contents}

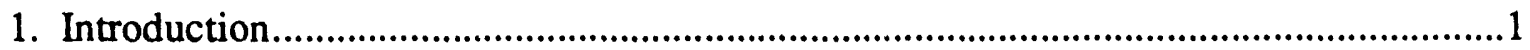

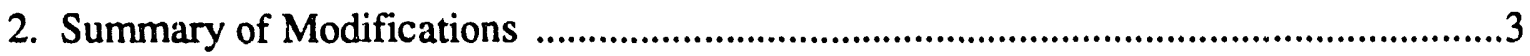

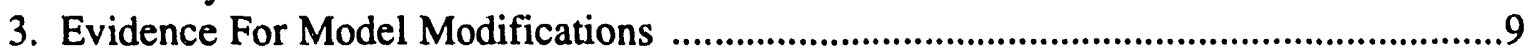

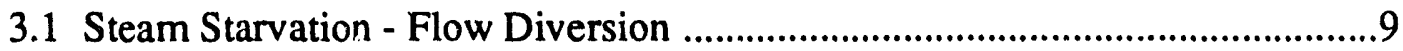

3.2 Diffusion Limit Of Steam Through Hydrogen .......................................11

3.3 Shattering Of Oxidized Cladding ...........................................................11

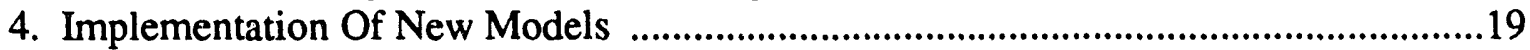

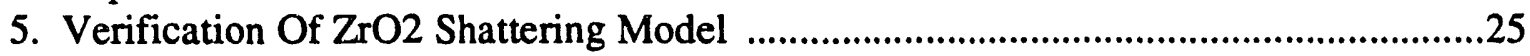

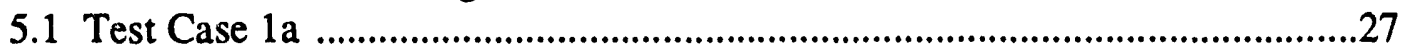

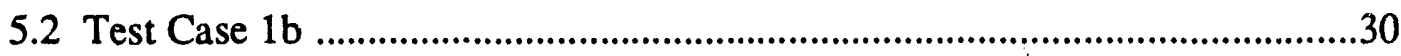

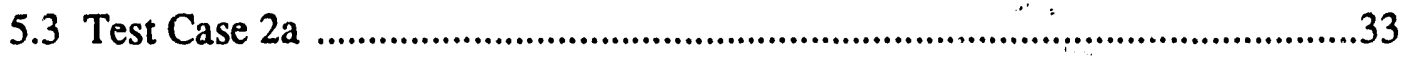

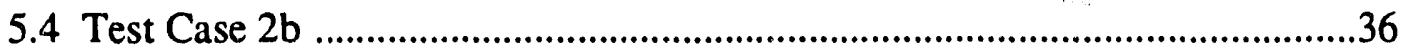

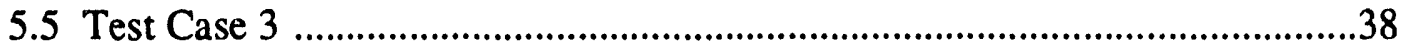

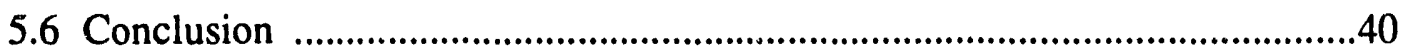

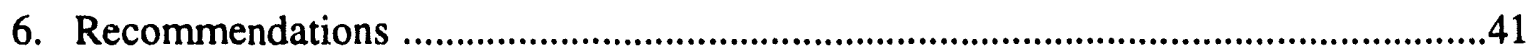

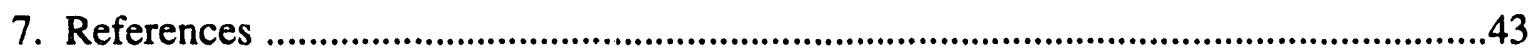




\section{LIST OF FIGURES}

Figure 1 Logic flow for oxidation model. .............................................................5

Figure 2 LOFT LP-FP-2 metallographic cross section I4 at $0.66 \mathrm{~m}$. ............................13

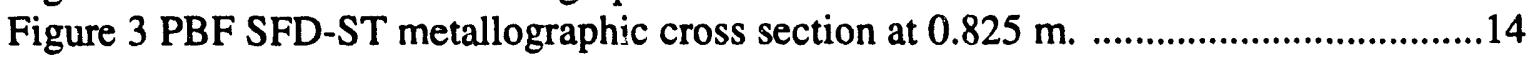

Figure 4 LOFT LP-FP-2 metallographic cross section G3 at $0.46 \mathrm{~m} . \ldots \ldots \ldots \ldots \ldots \ldots \ldots \ldots \ldots . . . \ldots 15$

Figure 5 Logic flow for reflood modifications. ..............................................................23

Figure 6 Logic flow for oxidation modifications. .....................................................24

Figure 7 Nodalization diagram of baseline input deck. ................................................26

Figure 8 Boundary and initial conditions for Case 1a. .............................................27

Figure $9 \beta$ phase thickness and surface temperature at axial node one for Case 1a. ........28

Figure 10 Surface temperature comparisons at axial node one for Case 1a. ...................30

Figure 11 Boundary and initial conditions for Case 1b. ................................................31

Figure $12 \beta$ phase thickness and surface temperature at axial node one for Case $1 \mathrm{~b} \ldots . . .32$

Figure 13 Hydrogen production vs. hydrogen availability for Case 1b. .........................33

Figure 14 Initial and boundary conditions for Case 2a. .................................................34

Figure $15 \beta$ phase thickness and surface temperature at axial node one for Case $2 \mathrm{a}$. ......35

Figure 16 Boundary and initial conditions for Case $2 b$. ...........................................36

Figure 17 Surface temperature history at axial node one for Case $2 b$. ............................37

Figure 18 Boundary and initial conditions for Case 3. ..................................................38

Figure $19 \beta$ phase thickness and surface temperature at axial node one for Case 3 . ........39 


\section{Introduction}

Current SCDAP/RELAP5 oxidation models have proven to underpredict oxidation, and therefore hydrogen production, when modeling reflood during in-pile tests. As an example, while OECD LOFT Experiment LP-FP-2 shows significant increases in temperature and pressure during reflood due to increased oxidation, only minimal additional oxidation is currently predicted with SCDAP/RELAP5. Since the code predicts a steam-rich environment during reflood, the parameter limiting oxidation must be the availability of zircaloy.

The addition of three models, to track phenomena not currently modeled, will improve the reflood oxidation capability of the code and should provide the necessary additional zircaloy oxidation during reflood. The three phenomena not currently modeled are: (1) localized steam starvation caused by debris blockage, (2) shattering of the protective oxide layer during reflood, and (3) oxidation of relocating/relocated debris. Localized steam starvation downstream of a core flow blockage may leave unoxidized zircaloy available for oxidation during reflood. Though evidence from LOFT points towards this mechanism, it was not observed in the PBF experiments. A second phenomenon that may expose zircaloy for oxidation is shattering of the protective oxide layer due to the thermal shock imposed by the strong thermal gradients experienced during reflood. A third phenomena thai is a factor in the oxidation rate, both prior to and during reflood, is oxidation of relocating debris. This phenomenon has not been considered here, since it is being addressed under a task to improve late-phase severe accident models.

The objective of this design report is to describe the development of new models to accurately predict zircaloy cladding oxidation during the temperature transients prior to and during reflood. Evidence compiled from postirradiation examination (PIE) of fuel bundles subjected to severe accident conditions from several in-pile tests is used to identify mechanisms for additional cladding oxidation during reflood and to develop specific criteria to determine when these mechanisms are applicable.

Section 2 of this report consists of a brief, qualitative description of the modifications to SCDAP/RELAP5. The reader is referred to Allison [1] for a complete description of the existing 
oxidation models. Section 3 documents the justification for each modification. This information includes evidence from PIE examination and posttest calculations of applicable experiments.

Detailed descriptions of model modifications are included in Section 4. Section 5 describes acceptance testing of the modifications, and Section 6 makes recommendations. 


\section{Summary of Modifications}

The workscope specified for this task identified three extensions to SCDAP/RELAP5.

These extensions are all directed towards correcting the identified deficiency of underpredicting the production of hydrogen during reflood. The extensions are:

- Flow diversion around debris blockage,

- Diffusion of steam across a hydrogen boundary layer, and

- Shattering of oxidized cladding.

The first two modifications obviously relate to steam starvation of the oxidation process, and therefore impose limitations on oxidation during the transient, thereby leaving additional zircaluy for oxidation during reflood. The final modification is independent of transient phenomena and exposes additional zircaloy surface at the initiation of reflood.

Flow diversion can be modeled in the current version of SCDAP/RELAP5 and does not require any code modifications. Given a sufficient number of parallel flow channels with the appropriate cross-flow junctions between each volume, current models will simulate flow diversion and any associated steam starvation. One of the limitations of this approach, however, is that the connecting volumes are assumed to be predominantly axial flow volumes in that the crossflow junction momentum flux, as well as the associated numerical viscous term, are neglected. This assumption, however, is ideally suited to calculations of core flow blockage. Despite this capability, little guidance is provided to the code user regarding when the use of multiple flow channels during the core flow blockage phase of the transient is needed. It is the intent of this task to provide such a user guideline.

When the oxidation process becomes significantly energetic, a hydrogen boundary layer can be established along the surface of the oxidizing component, and diffusion of steam across this hydrogen boundary layer limits the rate of zircaloy oxidation. One of the limitations of performing an analysis of oxidation is that a set of bulk conditions for the volume above the oxidizing surface must be applied along the surface as well as in the flow stream. A code extension has therefore been identified to impose a limit on zircaloy oxidation such that the reaction rate does 
not exceed the availability of oxygen due to diffusion across a hydrogen boundary layer.

The extension to provide enhanced oxidation during reflood will require code modifications to simulate the spalling or cracking of the protective oxide film. However, the basic high-temperature oxidation rate equations will remain unchanged. High-temperature oxide layer thickness, oxygen weight gain, and alpha layer thickness are all derived from parabolic rate equations [2,3];

$$
\frac{d \delta}{d t}=\frac{A}{\delta} e^{-B / T}
$$

where

$\delta=$ the rate of growth of oxide layer, oxygen weight gain, or alpha phase thickness,

$\mathrm{T}=$ temperature $(\mathrm{K})$,

$\mathrm{t}=$ time $(\mathrm{s})$,

A,B =parabolic rate constants taken from MATPRO [4].

This parabolic rate relationship is coupled to transient heat transfer behavior through the exothermic heat, and resultant temperature increases, produced during the conversion of zircaloy to $\mathrm{ZrO}_{2}$. Limiting factors include the availability of unoxidized zircaloy and the availability of steam.

Figure 1 illustrates the manner in which the reflood oxidation extensions will mesh with existing and future models. Beginning at the top, the code will first examine the potential for insufficient radial nodalization under flow blockage conditions by estimating the current recirculation volume and issuing a message to the user if such potential exists. Then, the oxidation limits due to either steam starvation or mass diffusion of steam across a hydrogen boundary layer are estimated.

The logic flow enters the reflood oxidation criteria by first examining the criteria for reflood and the $\beta$ phase thickness. If either of these criteria are not met, then the logic flow is, obviously, diverted around the reflood oxidation model. A failure from the third part of the criteria, that of 


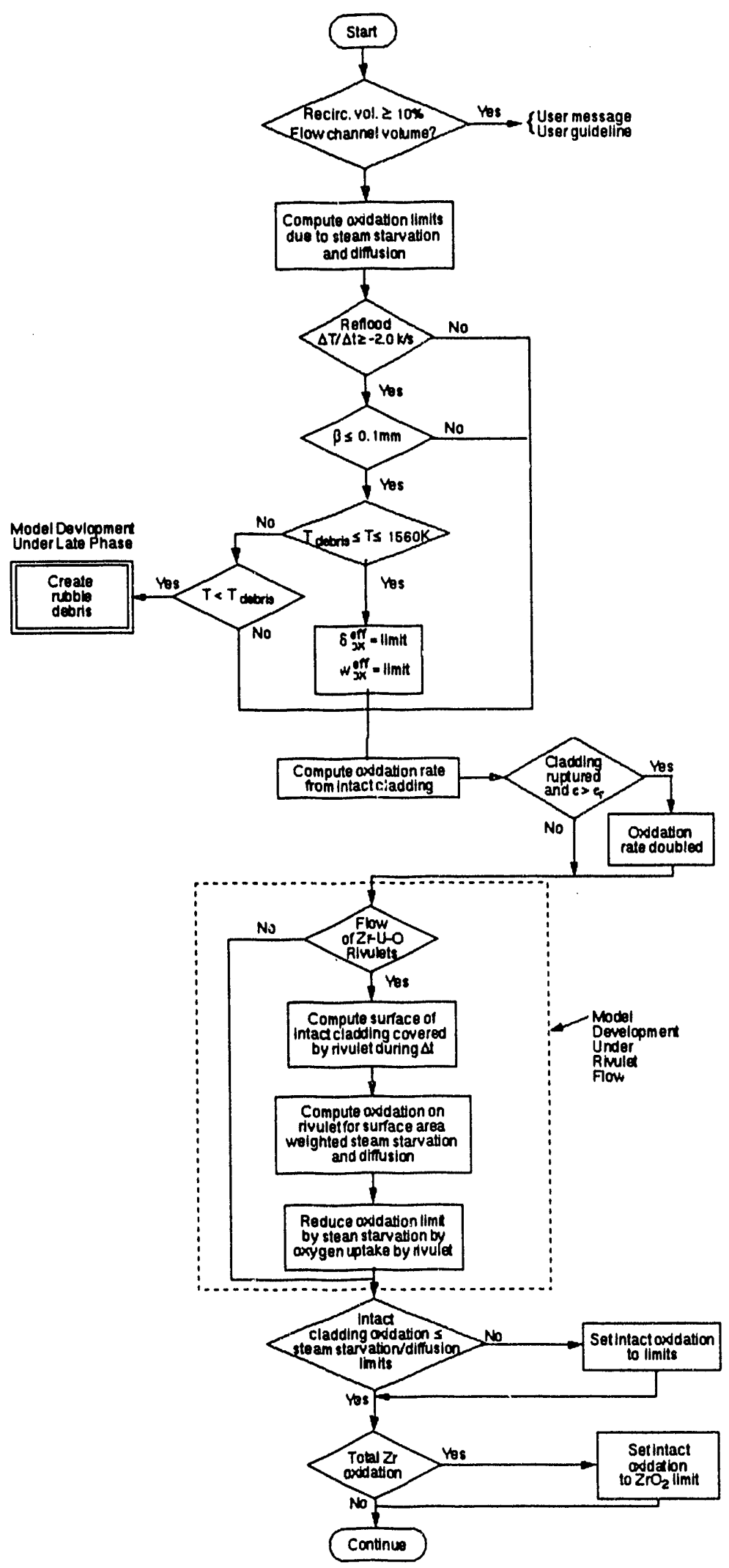

Figure 1 Logic flow for oxidation model. 
the oxide surface temperature being within the shattering range, will, in the future, allow the logic flow to enter a rubble debris bed model that is being considered under the late-phase model development. If the three reflood oxidation criteria are met, then the effective oxide layer thickness and the effective oxygen weight gain will be set to their lower limits. As described in the model implementation section, this effective oxide thickness and effective weight gain will be used in the parabolic rate equations.

The lower half of Figure 1 also illustrates the logic flow for the existing oxidation model and the manner in which that logic flow will mesh with the $\mathrm{Zr}-\mathrm{U}-\mathrm{O}$ rivulet flow model now being planned. The box representing the calculation of the oxidation based on intact cladding is somewhat deceiving, because there are two different models for this calculation, steady-state and transient. The steady-state model for calculation of oxidation does not allow feedback from the oxidation heating to change the cladding temperature during a single time step, and therefore assumes slow heating rate conditions. The transient model uses a simultaneous differential equation solver to model the fast heating conditions that require feedback from the oxidation heating to the cladding temperature. As shown in the logic flow diagram, if the cladding is ruptured and if double-sided oxidation is being modeled, then the oxidation rate is doubled.

Continuing, the logic flow enters the rivulet flow model, enclosed by a dotted line, which is planned for future development. This model will track rivulets of molten core material flowing along the outside of core components, whereas the existing liquid film flow model completely coats the surface of core components as it flows downward. While the existing model could allow a molten zircaloy film to oxidize, such a model would overpredict available zircaloy surface area and would significantly overpredict oxidation. The rivulet flow model provides a more physically realistic model of molten material relocation and should therefore provide a more realistic oxidation rate of relocating material. Finally, the logic flow sets physical limits on the oxidation rate, first to assure that no more steam can be consumed than is present and second to assure that no more $\mathrm{Zr}$ can be consumed than is present. 
The modifications described in this report should correct the trend of the current oxidation model to underpredict oxidation when it is applied to reflood conditions. They should also mesh well with current and planned capabilities of the SCDAP./RELAP5 models of core behavior under accident conditions. 
This page intentionally blank. 


\section{Evidence For Model Modifications}

The modifications discussed in the previous section are supported by experimental evidence from the following reports, referenced by author in Section 7.:

Carboneau, 1989 (LOFT), [5]

Hofmann, 1988 (PBF-SFD Sil) [6]

Jensen, 1989 (LOFT) [7]

Knipe, 1986 (PBF-SFD ST) [8]

Martinson, 1989 (PBF-SFD 1-3) [9]

Minato, 1991 (CORA) [10]

\subsection{Steam Starvation - Flow Diversion}

The formation of an impermeable or semi-permeable blockage in a reactor core may cause flow to be diverted around the blockage, which, in turn, may lead to localized steam starvation. If the facility being modeled has isolated flow channels, such as in an experimental facility or in a BWR, and if the blockage is large with respect to the flow area of the coolant flow channel, flow may be diverted to adjacent channels. Carboneau et al. [Ref 5, pp.83-85] investigated the possibility that flow diversion to peripheral assemblies occurred during the LOFT LP-FP-2 experiment. Based on upper plenum thermocouple data, it was concluded that some steam flow diverted around the center fuel module. Localized steam starvation from flow diversion has been hypothesized by Jensen [7] to account for the apparent availability of fresh zircaloy metal for oxidation during reflood in this experiment. In contrast, if the blockage is small with respect to the flow area of the coolant channel, flow may not be diverted to adjacent channels but may be diverted around the blockage within the same coolant channel. This creates a recirculation zone behind the blockage, with recovery of the original flow velocity much further downstream.

The suggested criterion for identifying when flow diversion should be modeled is based on experimental studies of recirculation flow behind blockages in rod bundle subchannels of liquid- 
metal cooled fast breeder reactors (LMFBRs). The size of the recirculation zone is used as the criterion for flow diversion steam starvation, because mass exchange rates in LMFBR recirculation zones have been measured to be less than $10 \%$ of the total mass flow rate [11].

Multiple channels should be considered to model steam starvation due to flow diversion when the volume of the recirculation zone exceeds $10 \%$ of the total volume in the channel. The volume of the recirculation zone is calculated assuming a cylindrical shape, where the bast diameter equals the effective diameter of the blockage and the length is the smaller of $5 \mathrm{~h}$ and $1.7 \mathrm{~d}$ (if the blockage is centrally located) or $2.5 \mathrm{~d}$ (if the blockage is located in a corner), where $\mathrm{h}$ is the height of the blockage and $d$ is the effective diameter of the blockage.

With the reduced mass exchange rate, little oxidation is expected to take place in the recirculation zone. Therefore, size of the recirculation zone (in percent total channel volume) can be used as an approximate value for the percent steam starvation. The $10 \%$ criterion is chosen on this basis. However, it should be noted that the relationship between actual steam starvation and recirculation zone size depends on zircaloy availability and steam density.

Length-to-height and length-to-diameter ratios are taken from studies performed by Kirsch [11] and Vegter et al. [12] for LMFBR geometries. These studies differ from LWR conditions in the lattice geometry and the Reynold's numbers. In LMFBR reactors, rods are assembled within a hexagonal fuel lattice, whereas in PWRs and BWRs, fuel rods are assembled within a square fuel lattice. The Kirsch study was performed at higher Reynold's numbers $(>10,000)$ than would be expected in LWR accident scenarios prior to reflood $(\operatorname{Re}<5000)$. Though the LMFBR ratios may not exactly predict LWR recirculation zone size, with such high turbulence, they are likely to specify a lower limit on the zone size.

When modeling flow diversion, as a minimum, there should be enough flow channels to define the blockage. Similarly, as a minimum, the axial volumes also must be small enough to define the blockage. Beyond the minimums, the proper numbers of axial volumes and radial channels to model flow diversion depend on the parameter (eg., temperature, pressure, hydrogen production) being monitored and the required precision, and are therefore transient-specific. 
Cross-flow resistances are found, iteratively, by matching the recirculation zone volume to the computed volume above. The recirculation zone is the region of separated or reversed flow behind a blockage. The number of radial channels, the number of axial volumes and the crossflow resistances must be established by the user, prior to the analysis.

\subsection{Diffusion Limit Of Steam Through Hydrogen}

Experimental evidence of oxidation reaction rates, limited by diffusion of steam through the hydrogen by-product, is not available. However, it is necessary and reasonable to assume that this limiting factor exists. The basis for this assumption is that when essentially clean zircaloy is exposed to the high-temperature steam environment experienced during a severe accident, an extremely energetic metal-water reaction occurs. Large quantities of hydrogen generated from the metal-water reaction would be sufficient to form a hydrogen boundary layer along the surface of the fuel rod under most flow conditions experienced during this phase of the accident. If this occurs, then the metal-water reaction rate would be limited by the rate of diffusion of steam across the hydrogen boundary layer. In this code extension, the oxidation reaction rate limited by the maximum diffusion of steam through a hydrogen layer, is calculated using a previously reported correlation [13]. This correlation specifies a diffusion coefficient of steam through the steam/ hydrogen mixture, and then utilizes the heat/mass transfer analogy to irnpose an upper limit on the metal-water reaction rate. Without this limitation, zircaloy oxidation would be overpredicted during any extremely energetic oxidation event, such as upon implementation of the shattering criterion, which is discussed below.

\subsection{Shattering Of Oxidized Cladding}

Shattered oxidized cladding debris was observed in LOFT LP-FP-2, SFD-ST, and CORA12 experiments, where each core was subjected to reflood. Figure 2 shows shattered cladding within the LOFT LP-FP-2 bundle, and Figure 3 shows shattered cladding fragments within the 
PBF SFD-ST bundle. PIE examination of the LOFT experiment reveals cladding remnants scattered through the upper blockage (Figure 4), which was formed during the reflood [Ref 14]. Whether a result of the force of the falling debris or the thermal shock during reflood, these cladding remnants had to have been formed during the reflood.

Direct comparison of comparable experiments with and without reflood is possible using , data from the CORA facility. Table 1 shows the posttest condition of simulator rod cladding after CORA-12, which was subjected to a reflood, while Table 2 shows the posttest condition of the simulator rod cladding after CORA-5, which did not experience reflood. These tables list the number of rods at a given location and cladding endstate condition. Table 1 shows that after the CORA-12 reflood a significant portion of the cladding was broken or missing, while Table 2 shows that CORA-5, with no reflood, experienced no extensive shattering, since shattering would have shown broken shards or missing cladding. Comparison of CORA-5 (no reflood) and CORA12 (with reflood) indicates that cladding was mechanically broken during the quench. Apparently, the cladding was brittle due to oxidation; thermal stresses induced by reflood caused the exposed surfaces to shatter, resulting in exposure of fresh metal that oxidized immediately [Ref $10, \mathrm{pp} .28$, 29]. This mechanism of oxidation also helps to explain the surge in temperatures and hydrogen production during reflood.

In the shattering model to be implemented, if the thickness of the $\beta$ phase is less than $0.1 \mathrm{~mm}$, the cladding fails. This is based on a study by Chung and Kassner [Ref 15, pp. 23-28] for fast-cooled cladding ( $100 \mathrm{~K} / \mathrm{s}$ through the phase transformation). Chung and Kassner found that "all tubes in which the thickness of the $\beta$ phase, with $\leq 0.9 \mathrm{wt} \%$ oxygen, was $\leq 0.1 \mathrm{~mm}$ thick failed, irrespective of the temperature, wall thickness of the deformed tube and total oxygen content of the material." [Ref 4, p. 28]. In order for zircaloy cladding to remain intact through the thermal shock conditions associated with reflood, there must be $\beta$ phase material with $\leq 0.9 \mathrm{wt} \%$ oxygen and this material must have a thickness $\geq 0.1 \mathrm{~mm}$. The associated physical phenomena is that the fully oxidized cladding has no inherent strength and the $\beta$ phase zircaloy carries the load.

Because SCDAP/RELAP5 uses parabolic rate equations to define oxidation, rather than a 


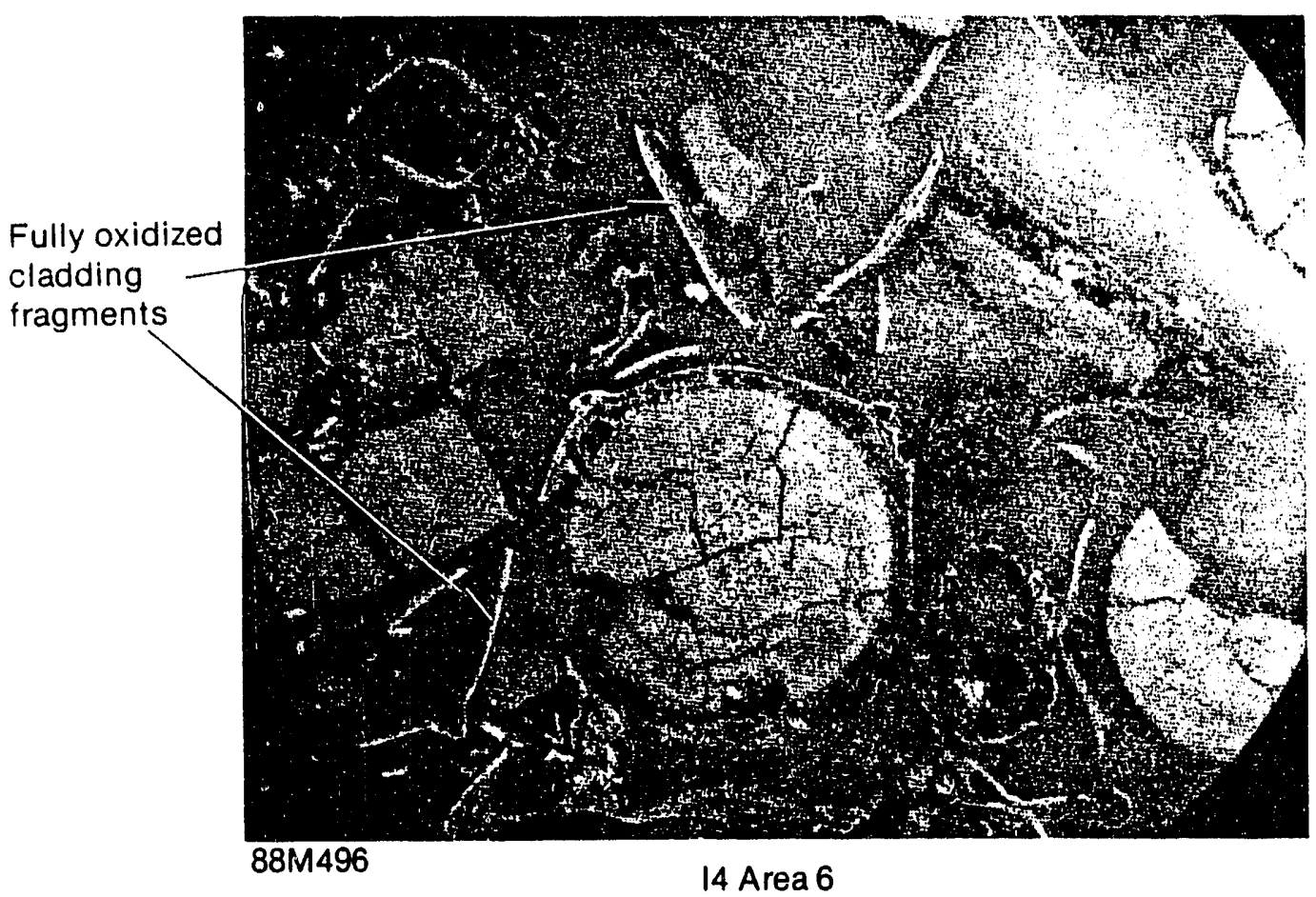

Figure 2 LOFT LP-FP-2 metallographic cross section I4 at $0.66 \mathrm{~m}$. 


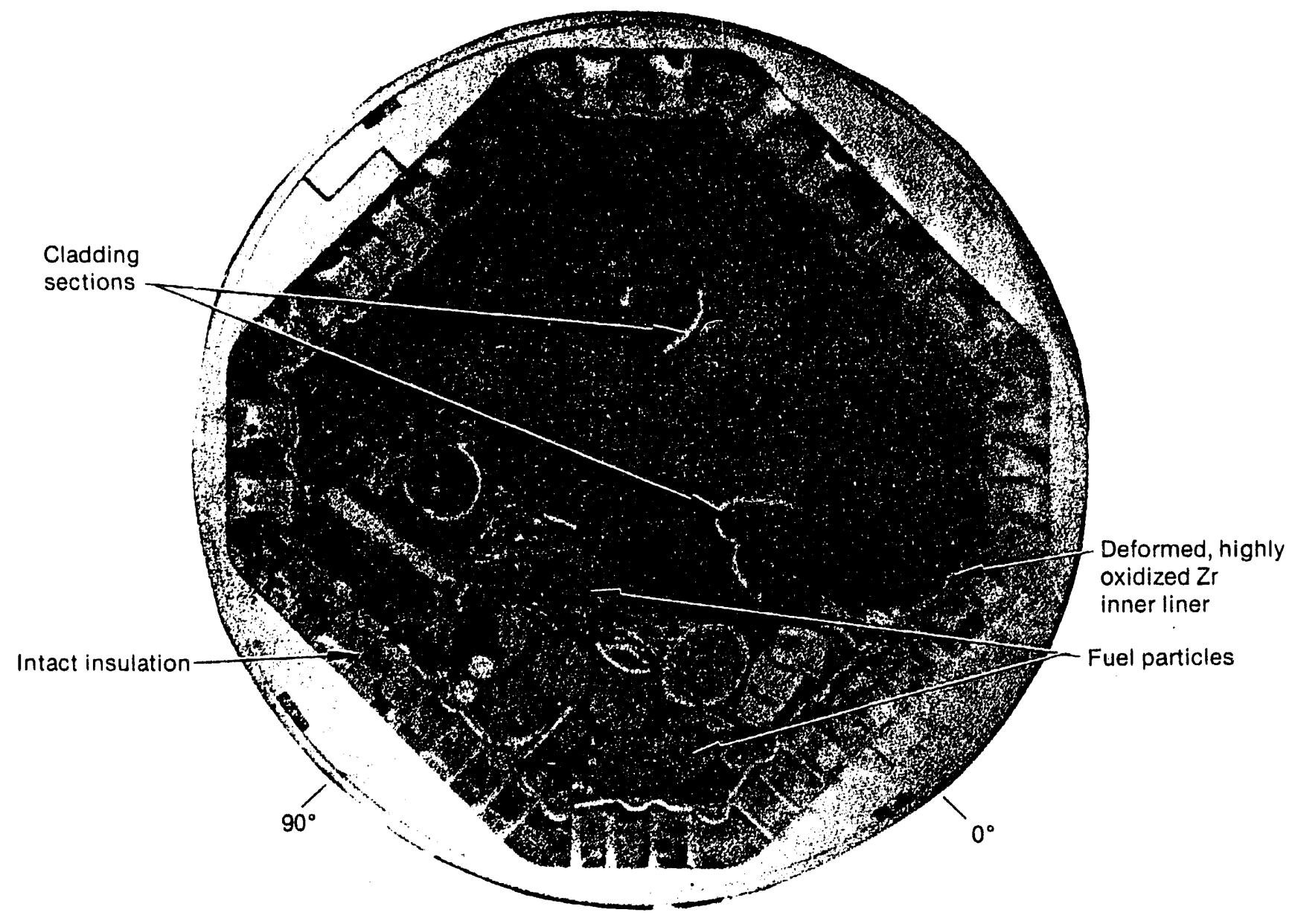

Figure 3 PBF SFD-ST metallographic cross section at $0.825 \mathrm{~m}$. 


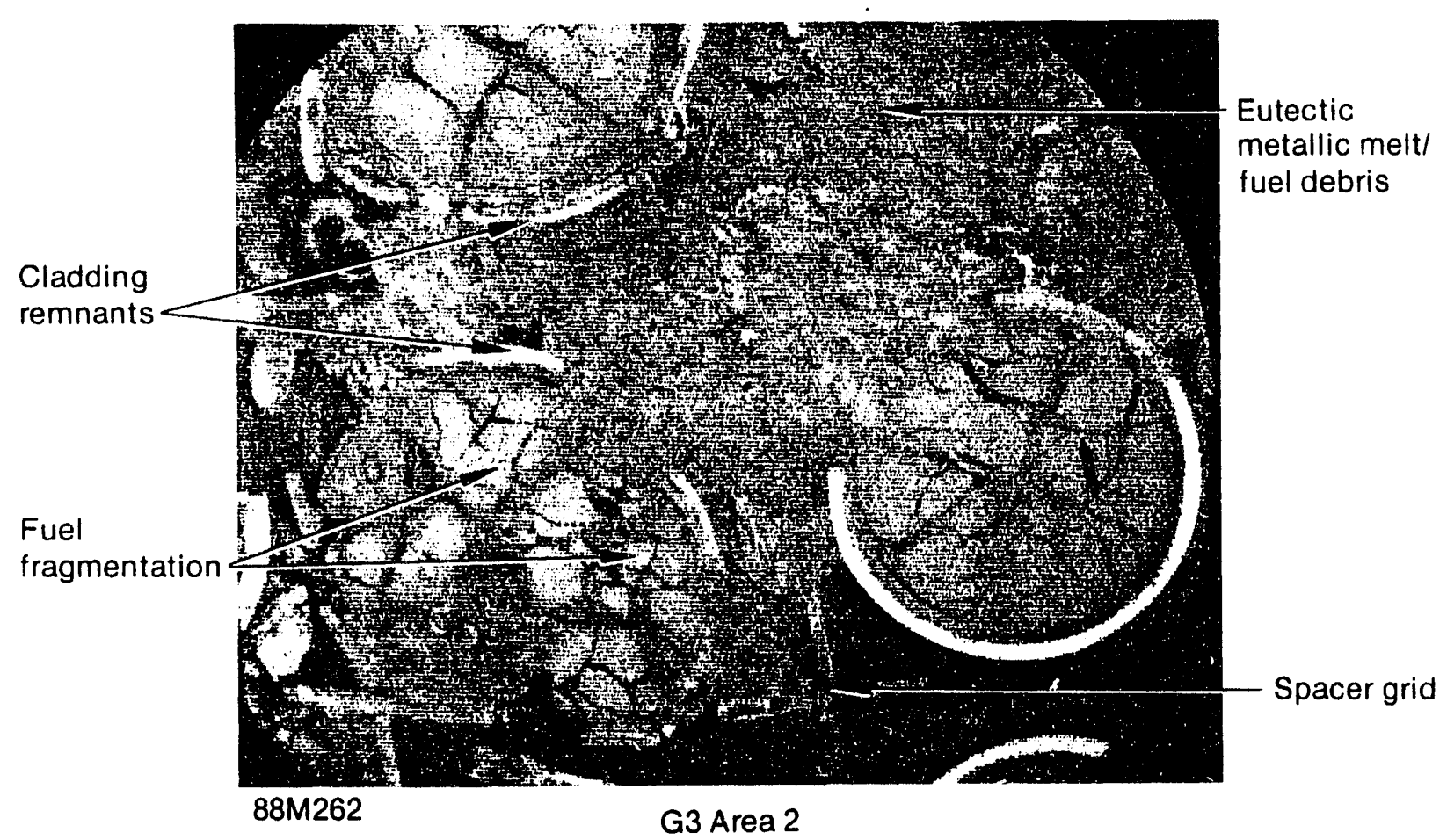

Figure 4 LOFT LP-FP-2 metallographic cross section G3 at $0.46 \mathrm{~m}$. 
Table 1 CORA-12 cladding posttest condition.

\begin{tabular}{|c|c|c|c|c|c|c|}
\hline $\begin{array}{c}\text { Elevation } \\
(\mathrm{mm})\end{array}$ & $\begin{array}{c}\text { Cladding } \\
\text { Intact }\end{array}$ & $\begin{array}{c}\text { Cladding } \\
\text { missing }\end{array}$ & $\begin{array}{c}\text { Cladding } \\
\text { reacted }\end{array}$ & $\begin{array}{c}\text { Cladding } \\
\text { flowered }\end{array}$ & $\begin{array}{c}\text { Cladding } \\
\text { broken: } \\
\text { mechanical }\end{array}$ & $\begin{array}{c}\text { Absorber } \\
\text { rod }\end{array}$ \\
\hline \hline 51 & 23 & 0 & 0 & 0 & 0 & 2 \\
\hline 216 & 0 & 9 & 6 & 0 & 8 & 2 \\
\hline 381 & 0 & 5 & 0 & 18 & 0 & 0 \\
\hline 503 & 0 & 16 & 0 & 7 & 0 & 0 \\
\hline 711 & 0 & 19 & 0 & 4 & 0 & 0 \\
\hline 876 & 2 & 15 & 0 & 6 & 0 & 0 \\
\hline
\end{tabular}

Table 2 CORA-5 cladding posttest condition.

\begin{tabular}{|c|c|c|c|c|c|c|}
\hline $\begin{array}{c}\text { Elevation } \\
(\mathrm{mm})\end{array}$ & $\begin{array}{c}\text { Cladding } \\
\text { intact }\end{array}$ & $\begin{array}{c}\text { Cladding } \\
\text { missing }\end{array}$ & $\begin{array}{c}\text { Cladding } \\
\text { reacted }\end{array}$ & $\begin{array}{c}\text { Cladding } \\
\text { flowered }\end{array}$ & $\begin{array}{c}\text { Cladding } \\
\text { broken: } \\
\text { mechanical }\end{array}$ & $\begin{array}{c}\text { Absorber } \\
\text { rod }\end{array}$ \\
\hline \hline 95 & 24 & 0 & 0 & 0 & 0 & 1 \\
\hline 208 & 23 & 0 & 1 & 0 & 0 & 1 \\
\hline 393 & 0 & 0 & 3 & 21 & 0 & 0 \\
\hline 408 & 0 & 0 & 2 & 22 & 0 & 0 \\
\hline 663 & 0 & 8 & 0 & 16 & 0 & 0 \\
\hline 853 & 0 & 10 & 0 & 14 & 0 & 0 \\
\hline
\end{tabular}

more complex diffusion model, the code does not calculate the profile of oxygen content through any phase. The proposed shattering criterion, therefore allows cladding to remain intact if the $\beta$ phase thickness is $\geq 0.1 \mathrm{~mm}$, irrespective of the oxygen content. However, from the zirconiumoxygen phase equilibrium diagram, it can be seen that for maximum temperatures less than 1560 $\mathrm{K}$, the oxygen content in the $\beta$ phase is less than $0.9 \mathrm{wt} \%$. So the proposed shattering criterion deviates from Chung and Kassner only for cases where the maximum cladding temperature exceeds $1560 \mathrm{~K}$. For such cases, cladding will be assumed to remain intact, and $\mathrm{Zr}$ oxidation may be underpredicted. 
One additional criteria is suggested for the shattering model. If the cooling rate from $1560 \mathrm{~K}$ to $1150 \mathrm{~K}$ (the $\alpha-\beta$ transformation temperatures for zirconium with $0.9 \mathrm{wt} \%$ oxygen) is greater than $2 \mathrm{~K} / \mathrm{s}$, and the Chung and Kassner $\beta$ phase criterion is met, then the cladding fails. This added criterion specifies a minimum cooling rate through a specific temperature region. Thermal shock failure is a result of high-temperature gradients (large temperature differences with respect to distance, not time). Minimum rates should be specified because, with slow cooling rates, the gradient is reduced and failure is less likely. In CORA-5, the zircaloy cladding survived a $2 \mathrm{~K} / \mathrm{s}$ cooling rate through the transition temperature without failure, whereas in the tests run by Chung and Kassner, failure was observed for cooling rates of $5 \mathrm{~K} / \mathrm{s}$. Cooling rates outside of the transformation temperature region are not considered in this criterion, because the failure mechanism is assumed to be associated with the transformation from $\beta$ phase (body-centered cubic) to $\alpha$ phase (hexagonal close pack). 
This page intentionally blank. 


\section{Implementation Of New Models}

In this section, a detailed description of the method of implementation of the new models in SCDAP/RELAP5 is presented. As stated earlier, modeling flow diversion around a core blockage does not require code modification but may require more flow channels to be added to an existing model. Steam diffusion through a hydrogen layer requires that the code be modified to impose an upper limit on the oxidation reaction rate, based on steam diffusion through hydrogen. The $\mathrm{ZrO}_{2}$ shattering model also requires code modifications to determine the conditions for shattering, plus provide a methodology to track the oxide shattering history.

The oxidation reaction rate limit based on the diffusion of steam through a boundary layer of hydrogen is calculated by first determining the diffusion coefficient of oxygen through the hydrogen boundary layer [13]. This diffusion coefficient, $\mathrm{D}_{\mathrm{H} 2 \mathrm{O}}$, is determined as follows:

$$
D_{\mathrm{H}_{2} \mathrm{O}}=\frac{R \times T}{P}\left(\frac{X_{\mathrm{H}_{2}} \mu_{\mathrm{H}_{2}}}{M_{\mathrm{H}_{2}}}+\frac{X_{\mathrm{H}_{2} \mathrm{O}} \mu_{\mathrm{H}_{2} \mathrm{O}}}{M_{\mathrm{H}_{2} \mathrm{O}}}\right)
$$

where

$$
\begin{aligned}
& R=\text { gas constant } \\
& T=\text { fluid temperature } \\
& P=\text { pressure } \\
& X_{\mathrm{H} 2}, X_{\mathrm{H} 2 \mathrm{O}}=\mathrm{H}_{2} \text { and } \mathrm{H}_{2} \mathrm{O} \text { mole fractions respectively } \\
& \mu_{\mathrm{H} 2}, \mu_{\mathrm{H} 2 \mathrm{O}}=\mathrm{H}_{2} \text { and } \mathrm{H}_{2} \mathrm{O} \text { absolute viscosity respectively } \\
& M_{\mathrm{H} 2}, M_{\mathrm{H} 2 \mathrm{O}}=\mathrm{H}_{2} \text { and } \mathrm{H}_{2} \mathrm{O} \text { molecular weights, respectively. }
\end{aligned}
$$

Then, applying the mass/heat transfer analogy, a mass transfer film coefficient, $\beta$, is determined as in

$$
\beta=\frac{D_{H_{2} o} \times S h}{D_{h}}
$$


where

$\mathrm{D}_{\mathrm{H} 2 \mathrm{O}}=$ diffusion coefficient of steam through the steam/hydrogen mixture

$\mathrm{Sh}=$ Sherwood number

$\mathrm{D}_{\mathrm{h}}=$ hydraulic diameter.

The maximum reaction rate is then simply

$$
\Gamma=\frac{\rho_{\mathrm{H}_{2} \mathrm{O}} \times \beta \times M_{\mathrm{Zr}}}{2 \times M_{\mathrm{H}_{2} \mathrm{O}}}
$$

where

$\Gamma=$ reaction rate of the $\mathrm{Zr}-\mathrm{O}$ reaction

$\rho_{\mathrm{H} 2 \mathrm{O}}=$ density of water

$\beta=$ mass transfer film coefficient

$\mathrm{M}_{\mathrm{Zr}}=$ molecular weight of $\mathrm{Zr}$

$\mathrm{M}_{\mathrm{H} 2 \mathrm{O}}=$ molecular weight of water.

The implementation of the reflood shattering model consists of an additional subroutine, SHATTR, to code the criteria for oxide shattering, and a change within the oxidation models to implement two parallel oxidie histories. The logic flow of the implementation of the SHATTR subroutine and the modifications to allow initialization of the model are shown in Figure 5, while the logic flow for the implementation of the parallel oxide histories is shown in Figure 6. The SHATTR subroutine was first introduced in version 83 , while the extensions to implement parallel oxide histories were introcisced in version 84.

Subroutine SHATTR is a stand-alone module that determines whether or not a reflood condition is being experienced. It is interesting to note that the reflood criteria can potentially be met repetitively during a reflood. For example, a reflood could be imposed that shatters the oxide layer. This would stop the quench, due to the additional heat generation, until the reflood cooling overcame the additional oxidation. If reflood cooling were overcome by the heat of oxidation, then quench conditions would be reinstated, reestablishing the conditions that meet the reflood criterion. Quench conditions would, consequently, reshatter the oxide. It should be noted that a part of the acceptance testing of this modification should include a quench of this nature, to verify 
the stability of the numerics under these conditions.

In additional to the shattering criteria described in this report, a Boolean variable has been introduced, which, when true, will shatter the oxide layer on all components at all axial nıdes. This Boolean variable is linked to a RELAP5 logical trip, which is specified on input. It should be noted that this Boolean variable is intended to be drastically conservative, since all in-core oxide is shattered, and should dramatically overpredict the rate of hydrogen production. This part of the model has been implemented to allow the user to estimate the maximum oxidation rate that could be experienced for a given transient.

There were two potential approaches to implementing the oxide shattering model within the oxidation routines. The first was to assume that when the reflood criteria were met, all zircaloy oxide within that node would spall away from the component, exposing fresh zircaloy for oxidation, with the oxide fragments falling into the debris bed models. The second was to assume that when the reflood criteria were met, cracks would form in the oxide layer, exposing fresh zircaloy for oxidation, but leaving the oxide within the component model. The two approaches would produce the identical resulting additional oxidation, since the additional exposed zircaloy surface area would be identical to the component surface area, but differ in the manner in which the zircaloy oxide mass balance is maintained. In the cracking approach, the oxide mass balance would be performed by the component routines, while in the spalling approach, the oxide mass balance would be performed in the debris bed routines. The difficulty with the spalling approach is that a debris bed may not yet be formed, and indeed, there is no assurance that it would ever be formed. While it is possible to add zircaloy oxide mass to debris bed variables prior to the formation of the debris bed, so that the oxide mass balance would be maintained once the debris bed was formed, it would be difficult to keep the user informed of oxide mass after reflood, but before debris bed formation. For these reasons the cracking approach was used: however it is recommended that this approach be reexamined in the future if rubble debris bed modifications are implemented.

In the implementation of the oxide shattering model, the oxidation model was modified to model two oxide histories, a physical oxide history and an effective oxide history. The physical 
oxide history is the same set of variables in use prior to this modification and is used for all the mass balance and heat conduction modelling. The effective oxide history has been added as two independent variables, the effective oxide thickness and the effective oxygen weight gain. These variables are, of course, tracked for each axial node of each component and are used as the denominator, $\delta$, in the parabolic rate equation $\frac{d \delta}{d t}=\frac{A}{\delta} e^{-B / T}$. When the reflood criteria are met, the effective oxide thickness is reset to model fresh unoxidized zircaloy, and the oxygen weight gain is reset to the difference between the physical oxygen weight gain and the oxygen in the removed oxide layer. 


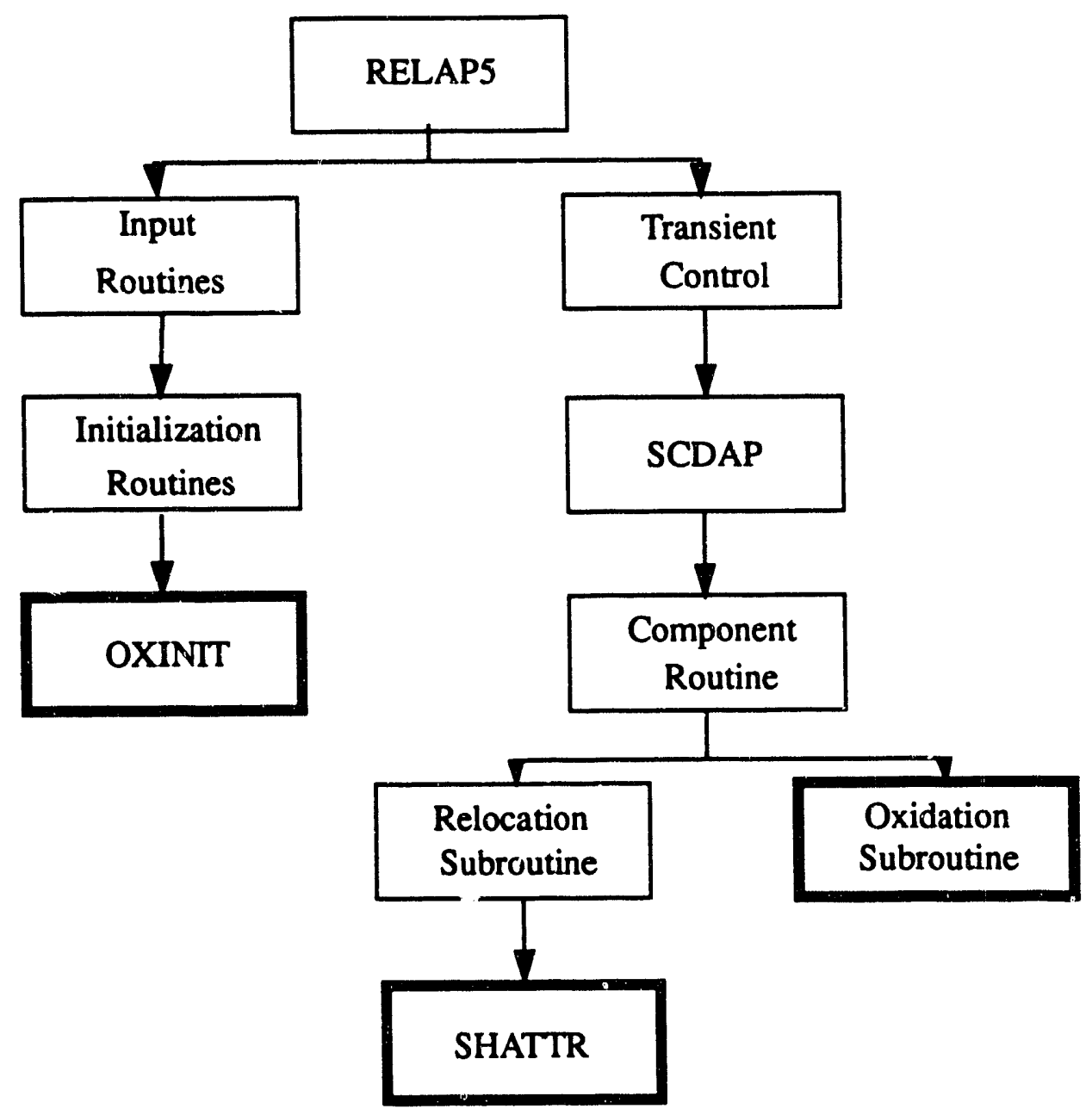

MODIFIED

ROUTINE

Figure 5 Logic flow for reflood modifications. 


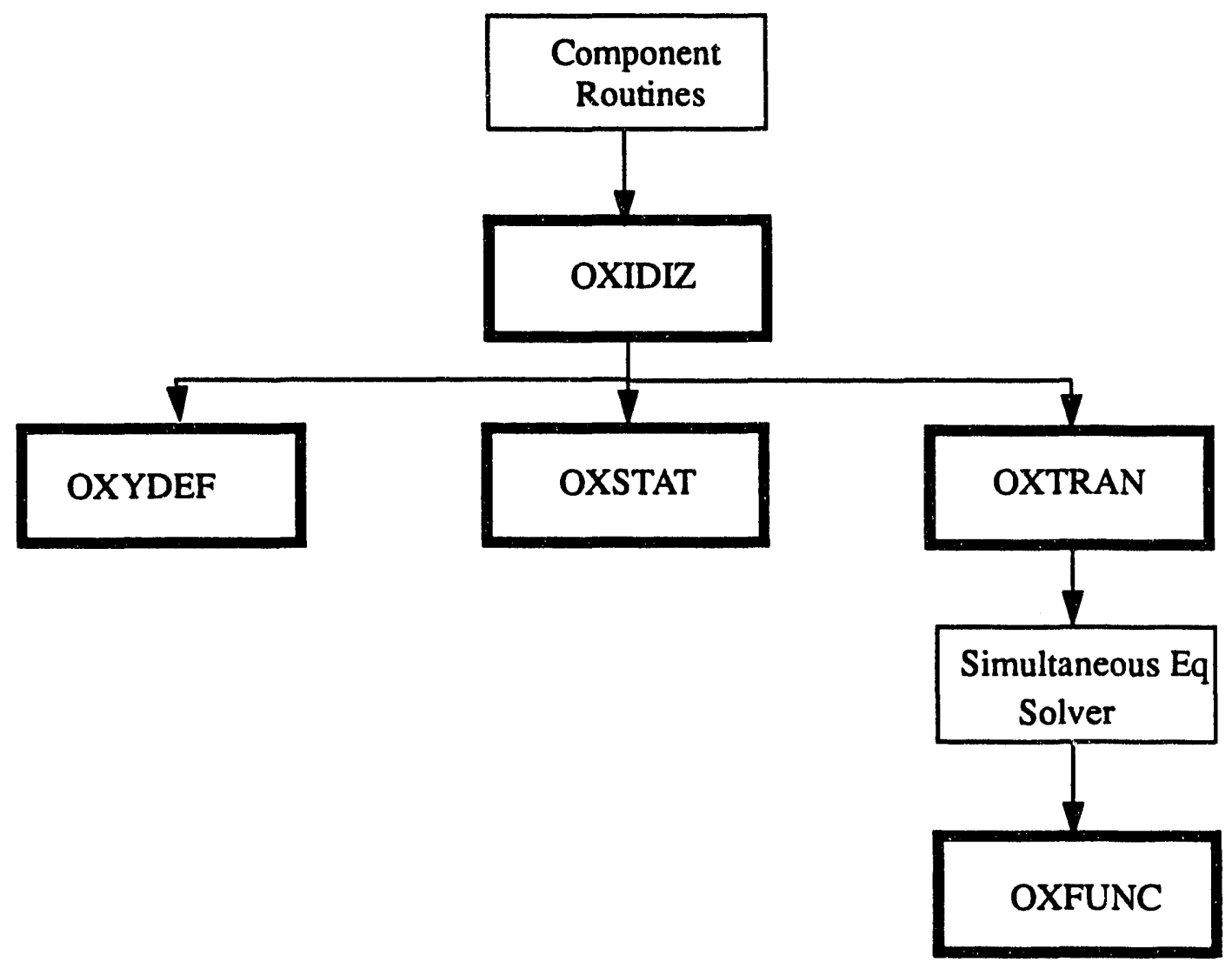

MODIFIED

ROUTINE

Figure 6 Logic flow for oxidation modifications. 


\section{Verification $\mathrm{Of} \mathrm{ZrO}_{2}$ Shattering Model}

Five test case problems were assembled to perform acceptance testing on the $\mathrm{ZrO}_{2}$ shattering model. The model was designed to shatter the oxide layer when both of the following criteria were met:

1) $\beta$ phase thickness less than or equal to $0.1 \mathrm{~mm}$,

2) Cooling rate greater than $2 \mathrm{~K} / \mathrm{s}$ for four consecutive time steps within the temperature range of $1150 \mathrm{~K}$ to $1560 \mathrm{~K}$.

The five test problems were pre-designed to exercise the limits of the criteria above. Test cases $1 \mathrm{a}$ and $1 \mathrm{~b}$ were designed to satisfy both of the criteria and initate the shattering model. Test cases $2 a, 2 b$, and 3 were designed to meet only one of the criterion and thus not initate the model. Each case was executed using version 83 of SCDAP/RELAP5/MOD3 with the $\mathrm{ZrO}_{2}$ shattering model added. For benchmarking purposes, test problem la was re-executed without the $\mathrm{ZrO}_{2}$ model on version 83 and the results were compared. A listing of the design parameters used for the five test problems is shown in Table 3.

Table 3 Test case design parameters.

\begin{tabular}{|c|c|c|c|c|c|}
\hline Test case & $\begin{array}{c}\text { Maximum core } \\
\text { surface temp. } \\
\text { prior to cooling }\end{array}$ & $\begin{array}{c}\text { Cooling rate in } \\
\text { temp. range of } \\
1150-1560 \mathrm{~K}\end{array}$ & $\begin{array}{c}\beta \text { phase } \\
\text { thickness prior } \\
\text { to cooling }\end{array}$ & $\begin{array}{c}\text { Satisfies } \\
\text { criterion 1 }\end{array}$ & $\begin{array}{c}\text { Satisfies } \\
\text { criterion 2 }\end{array}$ \\
\hline $1 \mathrm{a}$ & $>1800 \mathrm{~K}$ & $>10 \mathrm{~K} / \mathrm{s}$ & $<0.1 \mathrm{~mm}$ & yes & yes \\
\hline $1 \mathrm{~b}$ & $1150-1560 \mathrm{~K}$ & $>2 \mathrm{~K} / \mathrm{s}$ & $<0.1 \mathrm{~mm}$ & yes & yes \\
\hline $2 \mathrm{a}$ & $>1560 \mathrm{~K}$ & $<2 \mathrm{~K} / \mathrm{s}$ & $<0.1 \mathrm{~mm}$ & yes & no \\
\hline $2 \mathrm{~b}$ & $<1150 \mathrm{~K}$ & $>2 \mathrm{~K} / \mathrm{s}$ & $<0.1 \mathrm{~mm}$ & yes & no \\
\hline 3 & $1150-1560 \mathrm{~K}$ & $>2 \mathrm{~K} / \mathrm{s}$ & $>0.1 \mathrm{~mm}$ & no & yes \\
\hline
\end{tabular}

Each test problem was a derivative of a skeletal baseline input deck. The baseline was a simple model with two source volumes, a lower plenum volume, a core volume, and a sink volume. A single SCDAP component with six axial nodes was used to model 5625 fuel rods in the core. All decks had nuclear heat generation disabled and the ballooning models were deactivated. RELAP variable and logic trips were used to initate cooling when the above design parameters were met. The parameters for each case were obtained by adjusting the following conditions: 
- Flow rates of the two source junctions

- Initial thermodynamic states of all volumes

- Initial temperature of fuel rods

- Initial $\beta$ phase thickness

Figure 7 illustrates the nodalization of the baseline input deck

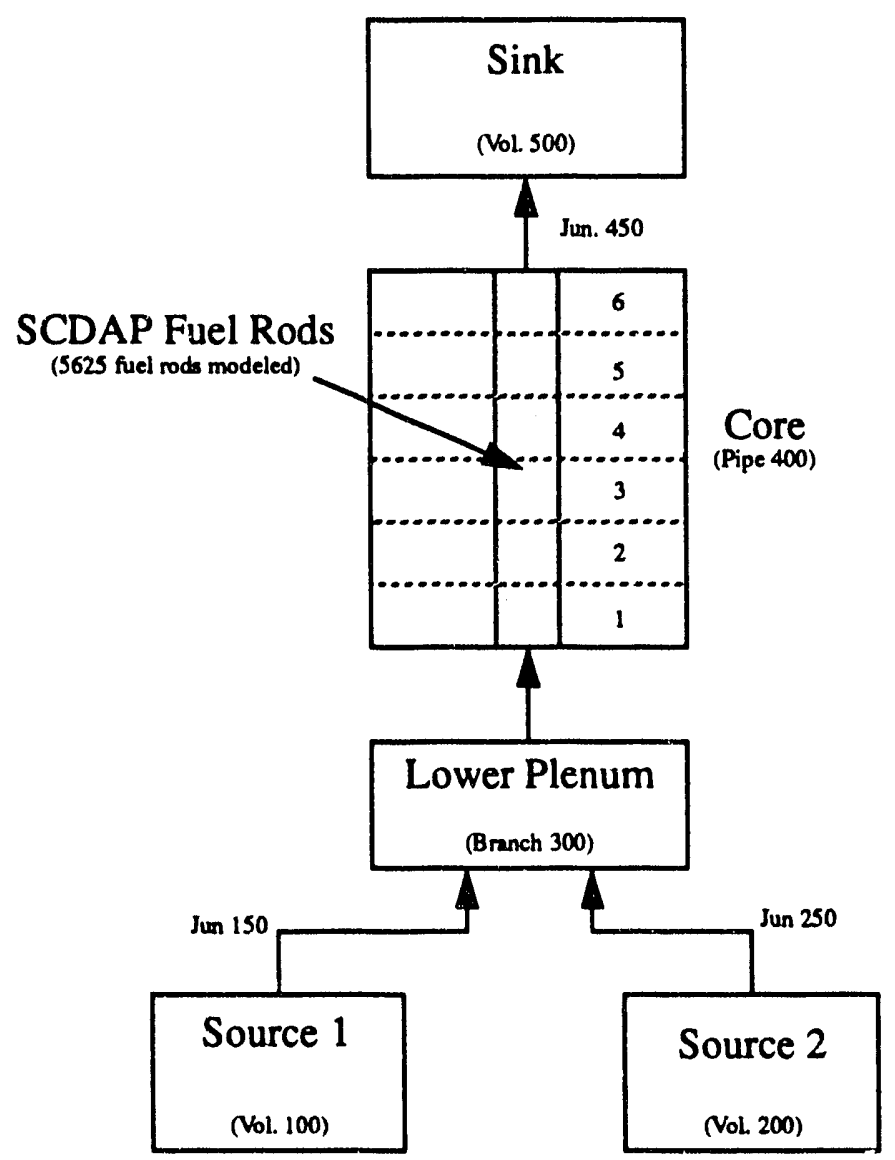

Figure 7 Nodalization diagram of baseline input deck. 


\subsection{Test Case 1a}

Test Case la was executed successfully to completion by satisfying both of the shattering model's criteria. The problem was designed to have core surface temperatures greater than $1800 \mathrm{~K}$, a cooling rate greater than $10 \mathrm{~K} / \mathrm{s}$ within the transition range of $1150 \mathrm{~K}$ to $1560 \mathrm{~K}$, and a $\beta$ phase thickness less than $0.1 \mathrm{~mm}$. Figure 8 shows the nodalization for Case 1a with boundary and initial conditions superimposed.

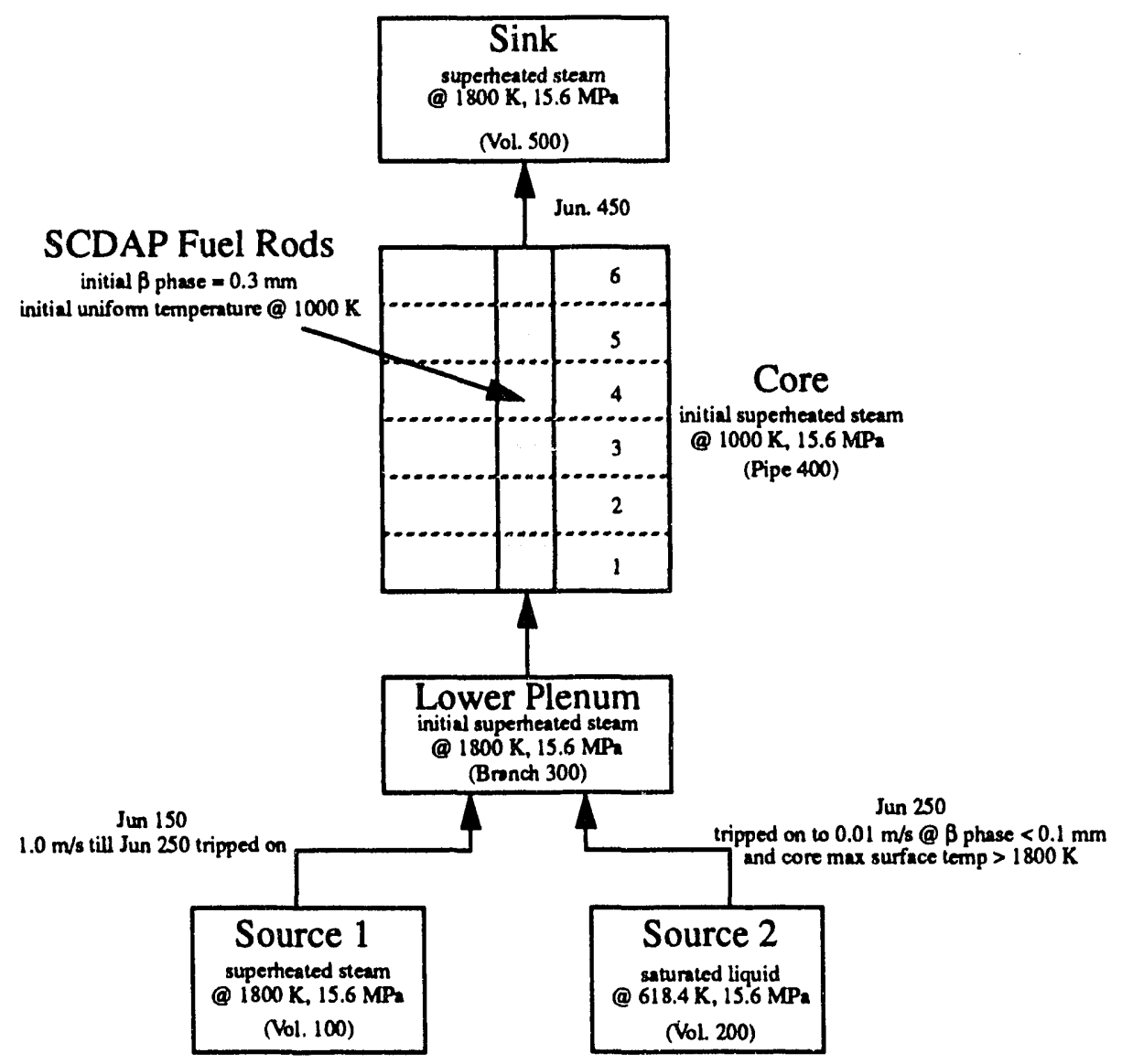

Figure 8 Boundary and initial conditions for Case 1a.

The core was heated with superheated steam at $1800 \mathrm{~K}, 15.6 \mathrm{MPa}$, with a velocity of $1.0 \mathrm{~m} / \mathrm{s}$ and cooled with saturated liquid at $15.6 \mathrm{MPa}$ with a velocity of $0.01 \mathrm{~m} / \mathrm{s}$. An initial $\beta$ phase thickness was set at $0.3 \mathrm{~mm}$, and the fuel rod temperatures were initiated at $1000 \mathrm{~K}$. RELAP trips were used to initiate cooling when the maximum core surface temperature was greater than $1800 \mathrm{~K}$ and the $\beta$ phase thickness was less than $0.1 \mathrm{~mm}$.

Case 1a experienced the highest core temperatures of all the test cases and had the greatest 
oxidation activity. Axial node one was the first to meet the problem parameters and will be the focus of this section. The $\beta$ phase thickness and surface temperature history plot for axial node one is shown in Figure 9.

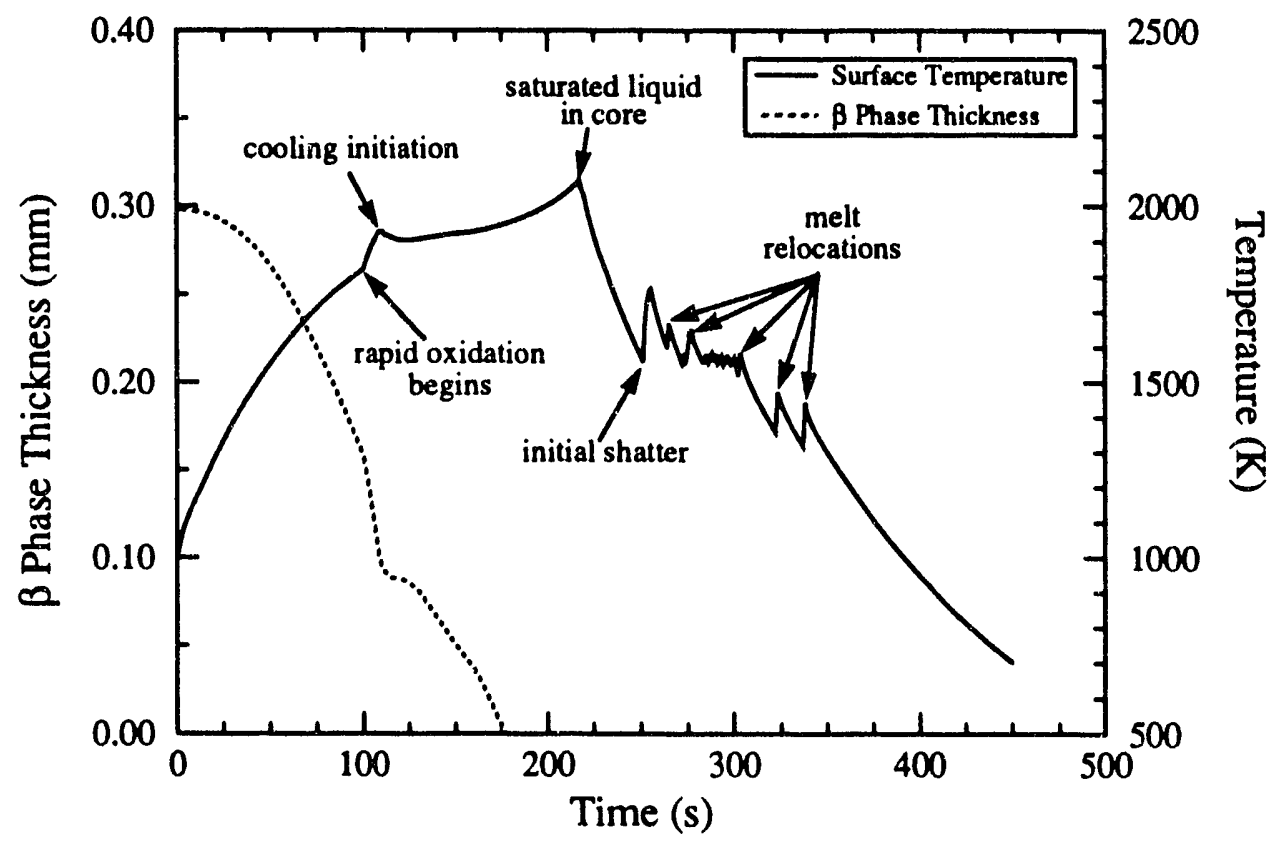

Figure $9 \beta$ phase thickness and surface temperature at axial node one for Case 1a.

Rapid oxidation prior to cooling at axial node one occurred at a problem time of 95 seconds as the surface temperature reached $1800 \mathrm{~K}$. Prior to rapid oxidation, the $\beta$ phase thickness was decreasing at a rate of $2.4 \times 10^{-3} \mathrm{~mm} / \mathrm{s}$; during rapid oxidation the rate jumped to $7.1 \times 10^{-3} \mathrm{~mm} / \mathrm{s}$. At 109 seconds, the problem parameters were satisfied and cooling was initiated. Surface temperatures continued to rise due to the drop in the mass flow rate as the lower plenum filled with saturated liquid. At 217 seconds, the saturated liquid reached the bottom of the core and rapid cooling began. The core cooled at an average rate of $15.5 \mathrm{~K} / \mathrm{s}$ within the transition temperature range of $1150 \mathrm{~K}$ to $1560 \mathrm{~K}$. The first oxide layer shattering occurred at 251 seconds, as the surface temperature reached $1560 \mathrm{~K}$. A temperature spike occurred after shattering when new unoxidized zircaloy was exposed to the cooling water. The new zircaloy was immediately oxidized, releasing enough heat to the upper axial nodes to cause melting and relocation. The melted material moved down the core and relocated at axial node one. This relocation caused a temperature increase until 
the cooling water could carry away the added heat. Additional shattering followed with the heating and cooling process. A total of five melt relocations to axial node one occurred. Oxidation and shattering continued until 300 seconds, when the remaining $\alpha$ layer was completely oxidized.

Table 4 lists the significant events and parameters for Case 1a.

Table 4 Significant events and parameters for Case 1a.

\begin{tabular}{|l|l|}
\hline Rapid oxidation prior to cooling & $95 \mathrm{~s}, 1800 \mathrm{~K}$ \\
\hline Maximum surface temperature prior to cooling at node one & $1928 \mathrm{~K}, 109 \mathrm{~s}$ \\
\hline Cooling initiation & $109 \mathrm{~s}$ \\
\hline$\beta$ phase deteriorated & $176 \mathrm{~s}$ \\
\hline Maximum surface temperature at node one & $2072 \mathrm{~K}, 217 \mathrm{~s}$ \\
\hline Saturated liquid reaches axial node one in core & $217 \mathrm{~s}$ \\
\hline Average cooling rate in temperature range $1150 \mathrm{~K}$ to $1560 \mathrm{~K}$ & $15.5 \mathrm{~K} / \mathrm{s}$ \\
\hline Initial oxide layer shatter & $251 \mathrm{~s}$ \\
\hline Complete oxidation of $\alpha$ phase & $300 \mathrm{~s}$ \\
\hline Melt relocation times & $264 \mathrm{~s}, 276 \mathrm{~s}, 303 \mathrm{~s}, 322 \mathrm{~s}, 337 \mathrm{~s}$ \\
\hline
\end{tabular}

Case 1a was re-executed without the $\mathrm{ZrO}_{2}$ shattering model installed on version 83 for benchmarking purposes. Surface temperature comparisons at axial node one are shown in Figure 10 for the two calculations. Both calculations yielded identical results until problem time $251 \mathrm{sec}-$ onds, which was the initial shatter time of the original calculation. After this time, the two calculations diverge. The original problem predicted rapid heatup and five melt relocations during reflood, whereas the sensitivity calculation showed no heatup or core damage during quenching. 


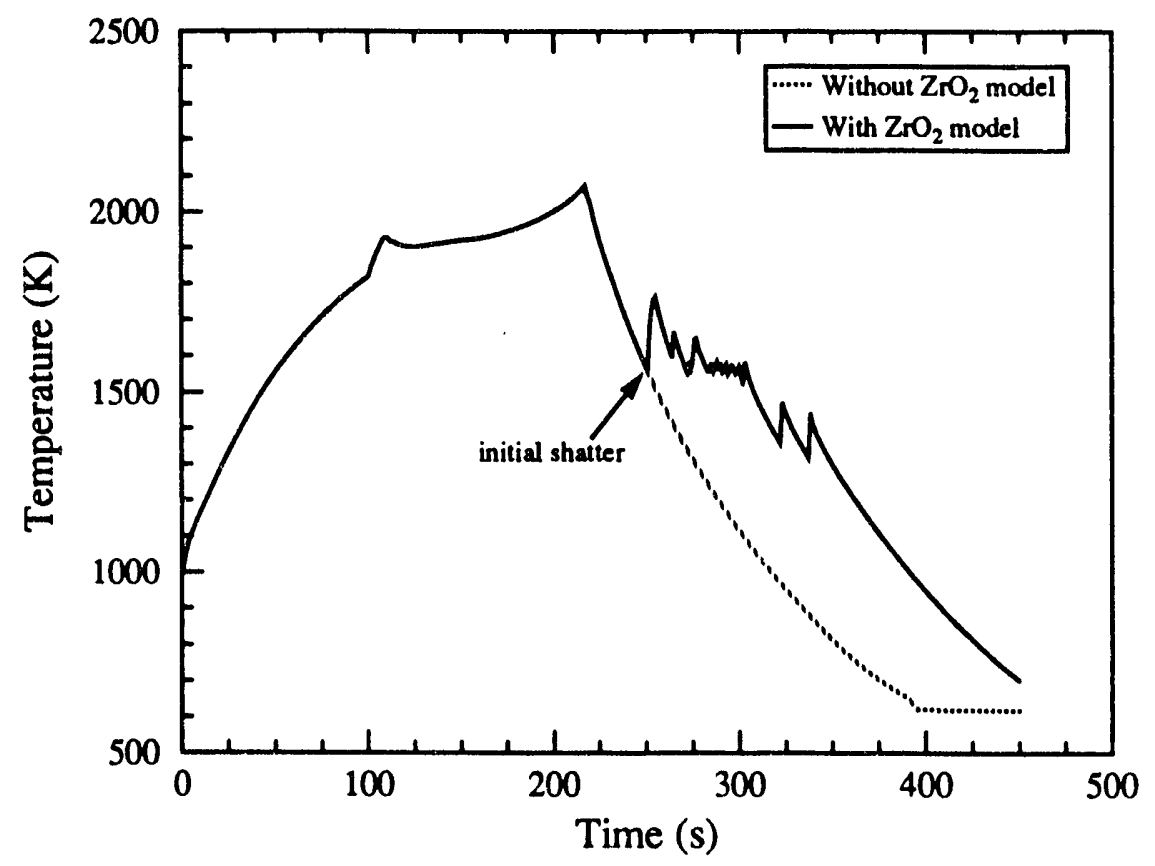

Figure 10 Surface temperature comparisons at axial node one for Case 1a.

\subsection{Test Case 1b}

Test Case $1 \mathrm{~b}$ was run to a successful completion by satisfying both of the shattering model's criteria. The problem was designed to have core surface temperatures within the transition range of $1150 \mathrm{~K}$ to $1560 \mathrm{~K}$, a cooling rate greater than $2 \mathrm{~K} / \mathrm{s}$, and a $\beta$ phase thickness less than $0.1 \mathrm{~mm}$. Figure 11 shows the nodalization of Case $1 \mathrm{~b}$ with the imposed boundary and initial conditions. The fuel rods were heated using superheated steam at $1500 \mathrm{~K}, 15.6 \mathrm{MPa}$, with a velocity of $0.8 \mathrm{~m} /$ s. The initial $\beta$ phase thickness was set at $0.2 \mathrm{~mm}$, and the fuel rod temperatures were initiated at $1000 \mathrm{~K}$. Cooling was provided by saturated liquid at $15.6 \mathrm{MPa}$ with a velocity of $0.01 \mathrm{~m} / \mathrm{s}$. Cooling initiation started when the maximum core surface temperature exceeded $1400 \mathrm{~K}$ and the $\beta$ phase thickness was less than $0.1 \mathrm{~mm}$. 


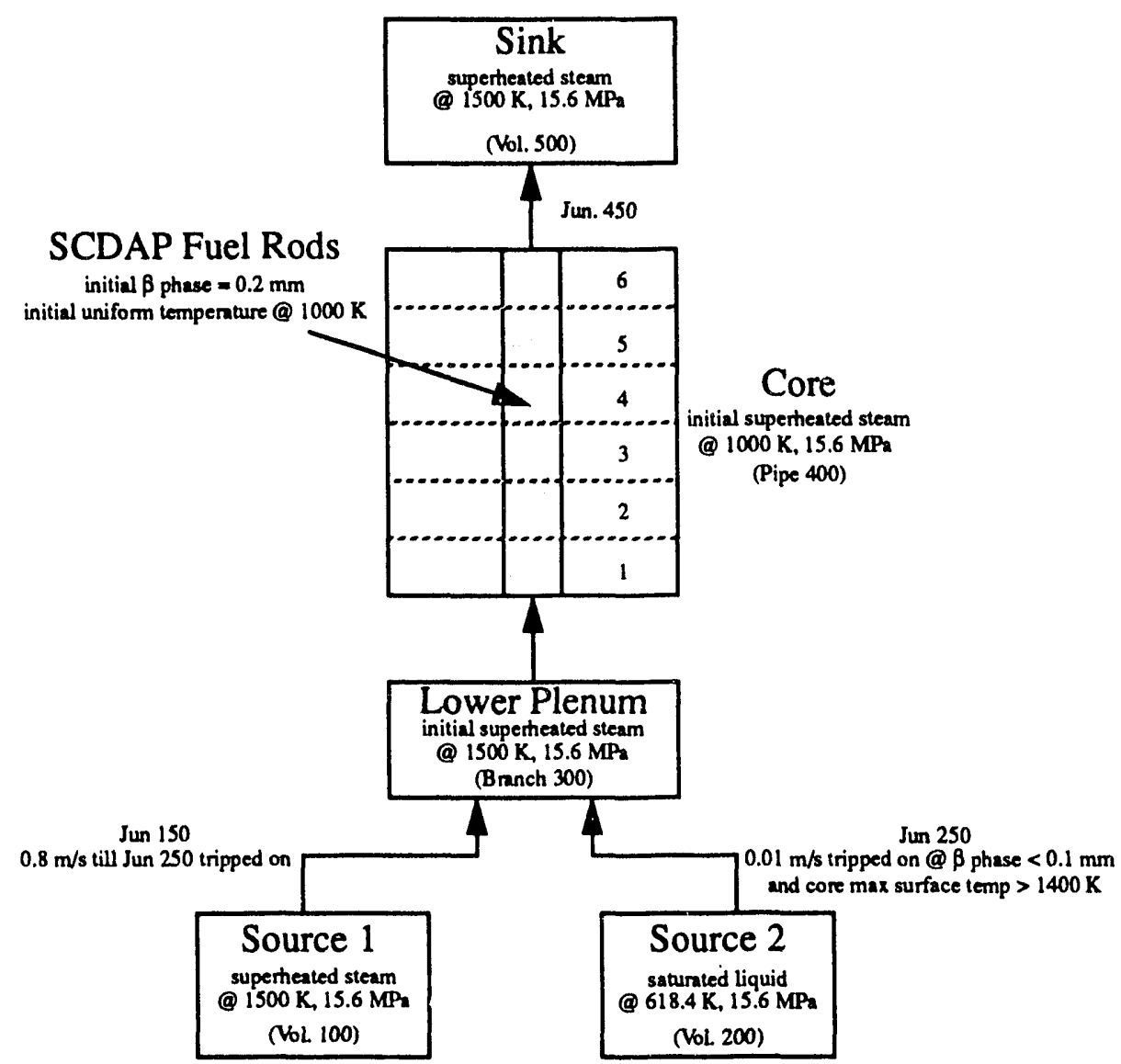

Figure 11 Boundary and initial conditions for Case $\mathbf{1 b}$.

Figure 12 shows the $\beta$ phase/surface temperature history plot for axial node one. Axial node one was the first node to experience oxide shattering and will be the focus of this section. Prior to cooling, a quasi-steady-state temperature of $1536 \mathrm{~K}$ was reached. At a problem time of $227 \mathrm{sec}$ onds, cooling was initiated when oxidation reduced the $\beta$ phase thickness below $0.1 \mathrm{~mm}$. Upon cooling initiation, the surface temperature at axial node one began to climb and peaked at $1546 \mathrm{~K}$. There are two reasons for the increase in temperature: 1) oxidation was on-going, and 2) the cooling capacity of th, fluid was reduced (i.e., the mass flow rate into the core dropped off sharply while the lower plenum was filled with saturated liquid). At a problem time of 335 seconds, saturated liquid reached the core, which resulted in an average cooling rate of $15 \mathrm{~K} / \mathrm{s}$. At a problem time of 336 seconds, the $\mathrm{ZrO}_{2}$ layer shattered at axial node one, causing increased oxidation heat 


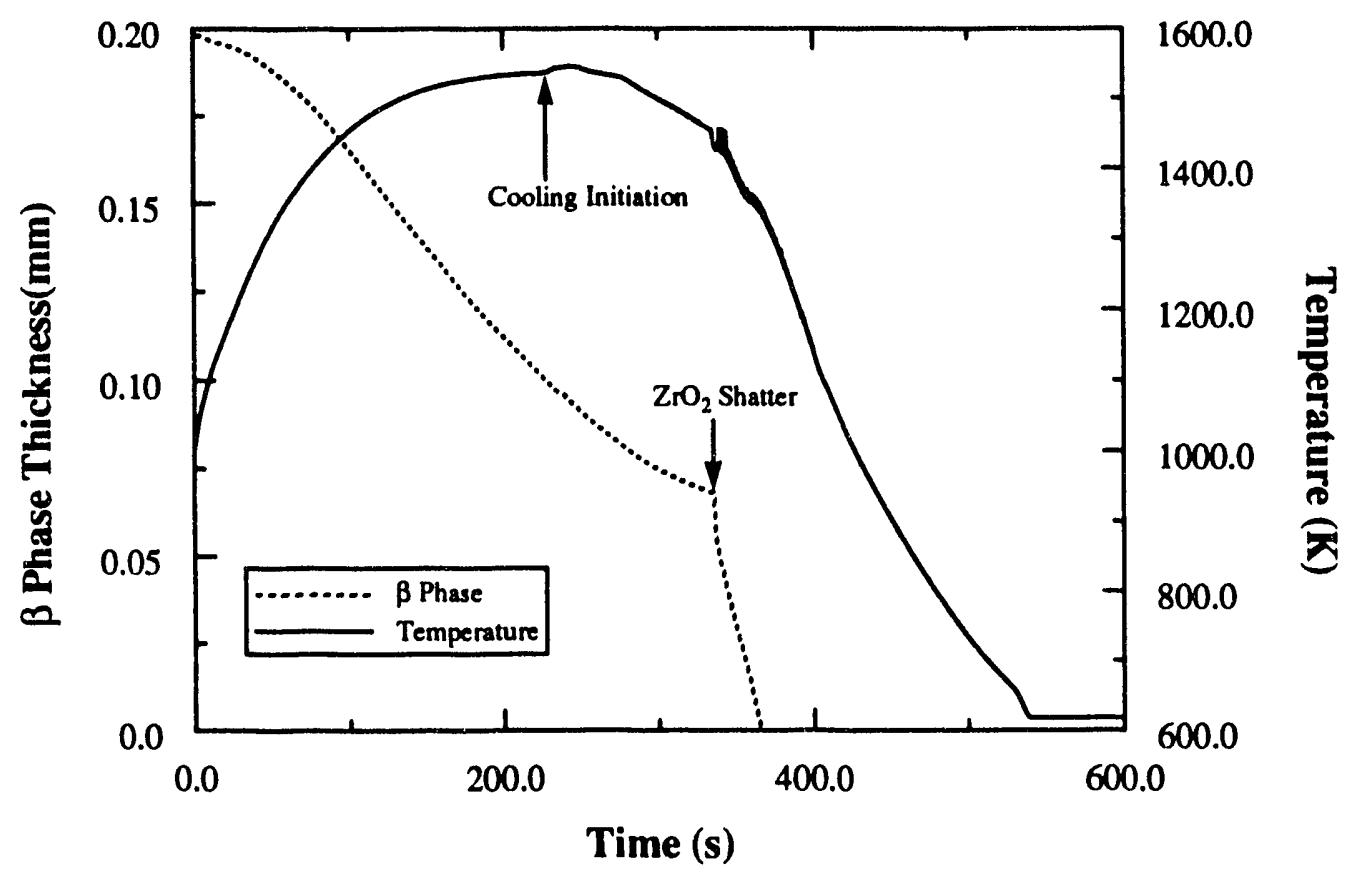

Figure $12 \beta$ phase thickness and surface temperature at axial node one for Case $1 \mathrm{~b}$

and a sharp increase in temperature. After the first $\mathrm{ZrO}_{2}$ shatter, the coolant was able to cool the surface at a rate greater than $2 \mathrm{~K} / \mathrm{s}$, resulting in a second shatter. The oscillatory behavior of shattering, heating, and cooling repeated until the surface temperature fell below $1150 \mathrm{~K}$ at a problem time of 399 seconds. From this time on, the fuel rods at axial node one were uneventfully cooled to the saturation temperature of $618 \mathrm{~K}$. Significant eveits and parameters are summarized in Table 5.

Table 5 Significant events and parameters for Case $1 \mathbf{b}$.

\begin{tabular}{|l|l|}
\hline Cooling initiation & $227 \mathrm{~s}$ \\
\hline Maximum surface temperature at axial node one & $1546 \mathrm{~K} @ 242 \mathrm{~s}$ \\
\hline Saturated liquid in core & $335 \mathrm{~s}$ \\
\hline Average cooling rate prior to $\mathrm{ZrO}_{2}$ shatter & $15 \mathrm{~K} / \mathrm{s}$ @ axial node 1 \\
\hline First $\mathrm{ZrO}_{2}$ shatter & $336 \mathrm{~s} @$ axial node 1 \\
\hline End of oxidation & $425 \mathrm{~s}$ \\
\hline
\end{tabular}

For Case $1 \mathrm{~b}$, hydrogen production was tracked. Figure 13 shows the plot of the hydrogen production plotted against the hydrogen availability. In this report, hydrogen availability is defined as 
the maximum hydrogen production rate that can be sustained for a given steam flow rate. For example, hydrogen availability for test Case $1 b$ is the mass flow rate into the core divided by nine. After the $\mathrm{ZrO}_{2}$ layer shattered, the hydrogen production rate increased and exceeded the oxygen availability, which resulted in steam-limited oxidation. The steam-limited oxidation continued for approximately 30 seconds. Liquefied cladding relocated at problem times 380, 393, 406 and 424 seconds into axial node two and effected hydrogen production. At problem time 425 seconds, hydrogen production ended. A total of $30.9 \mathrm{~kg}$ of hydrogen was produced for this run. This corresponds to $86 \%$ of the zircaloy being consumed at the end of the oxidation reaction.

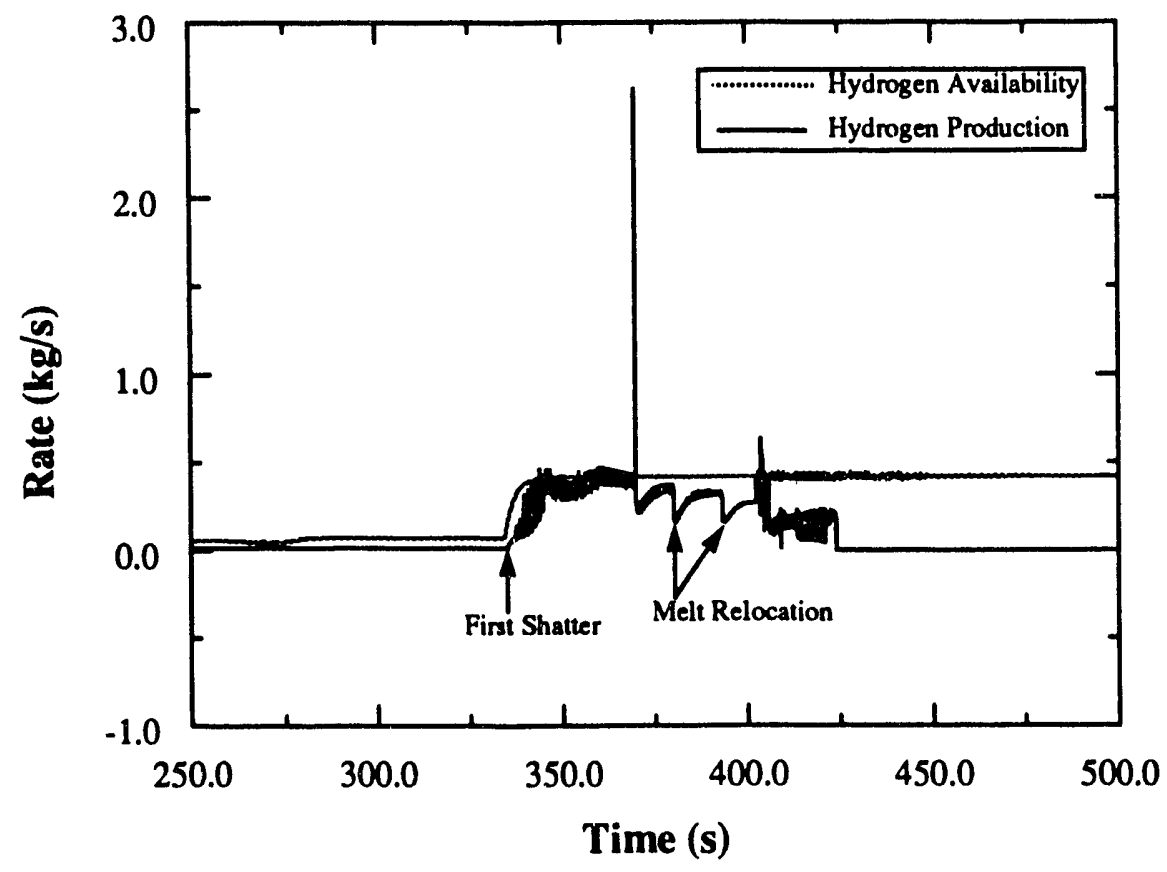

Figure 13 Hydrogen production vs. hydrogen availability for Case $1 \mathrm{~b}$.

\subsection{Test Case 2a}

- Test Case 2a was executed to a successful completion with no $\mathrm{ZrO}_{2}$ shattering. The test problem was designed to produce core surface temperatures greater than $1560 \mathrm{~K}$, a cooling rate less than $2 \mathrm{~K} / \mathrm{s}$ within the transition temperature range of $1150 \mathrm{~K}$ to $1560 \mathrm{~K}$ and a $\beta$ phase thickness less than $0.1 \mathrm{~mm}$. With these design parameters, only criterion 1 was met and shattering did not occur. Figure 14 shows the nodalization for Case 2a with boundary and initial conditions superim- 
posed.

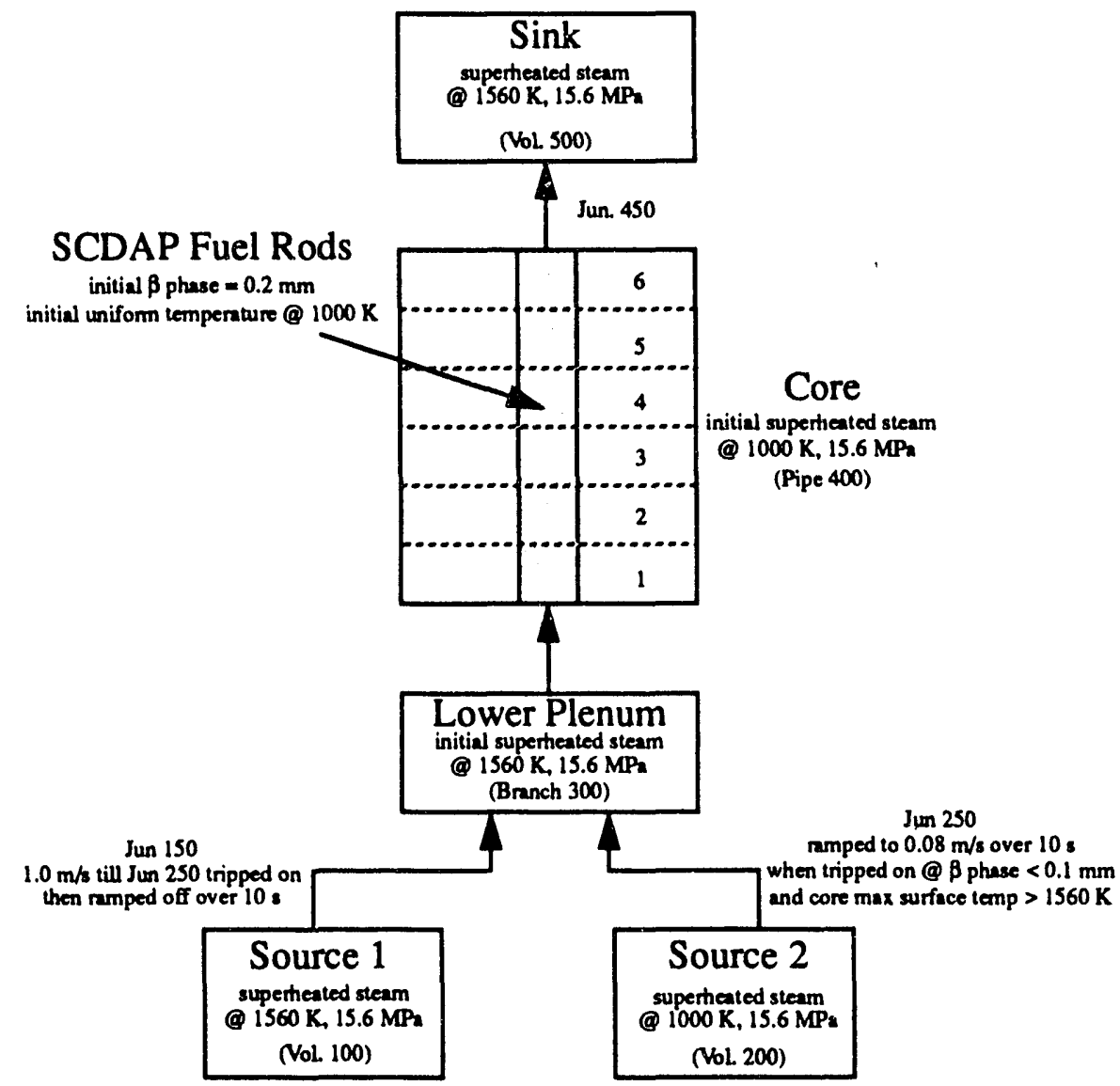

Figure 14 Initial and boundary conditions for Case $2 a$.

The core was heated with superheated steam at $1560 \mathrm{~K}, 15.6 \mathrm{MPa}$, with a velocity of $1.0 \mathrm{~m} / \mathrm{s}$ and cooled with superheated steam at $1000 \mathrm{~K}, 15.6 \mathrm{MPa}$ with a velocity of $0.08 \mathrm{~m} / \mathrm{s}$. The initial $\beta$ phase thickness was set at $0.2 \mathrm{~mm}$, and the fuel rods were initialized at a uniform temperature of $1000 \mathrm{~K}$. RELAP trips were set to initate cooling when the maximum core surface temperature was greater than $1560 \mathrm{~K}$ and the $\beta$ phase thickness was less than $0.1 \mathrm{~mm}$. The $\beta$ phase thickness and core surface temperature history plots for axial node one are shown in Figure 15. Axial node one was the first to meet the trip parameters and successfully pass through the transition temperature range of $1150 \mathrm{~K}$ to $1560 \mathrm{~K}$ without shattering and is the focus of this section. 


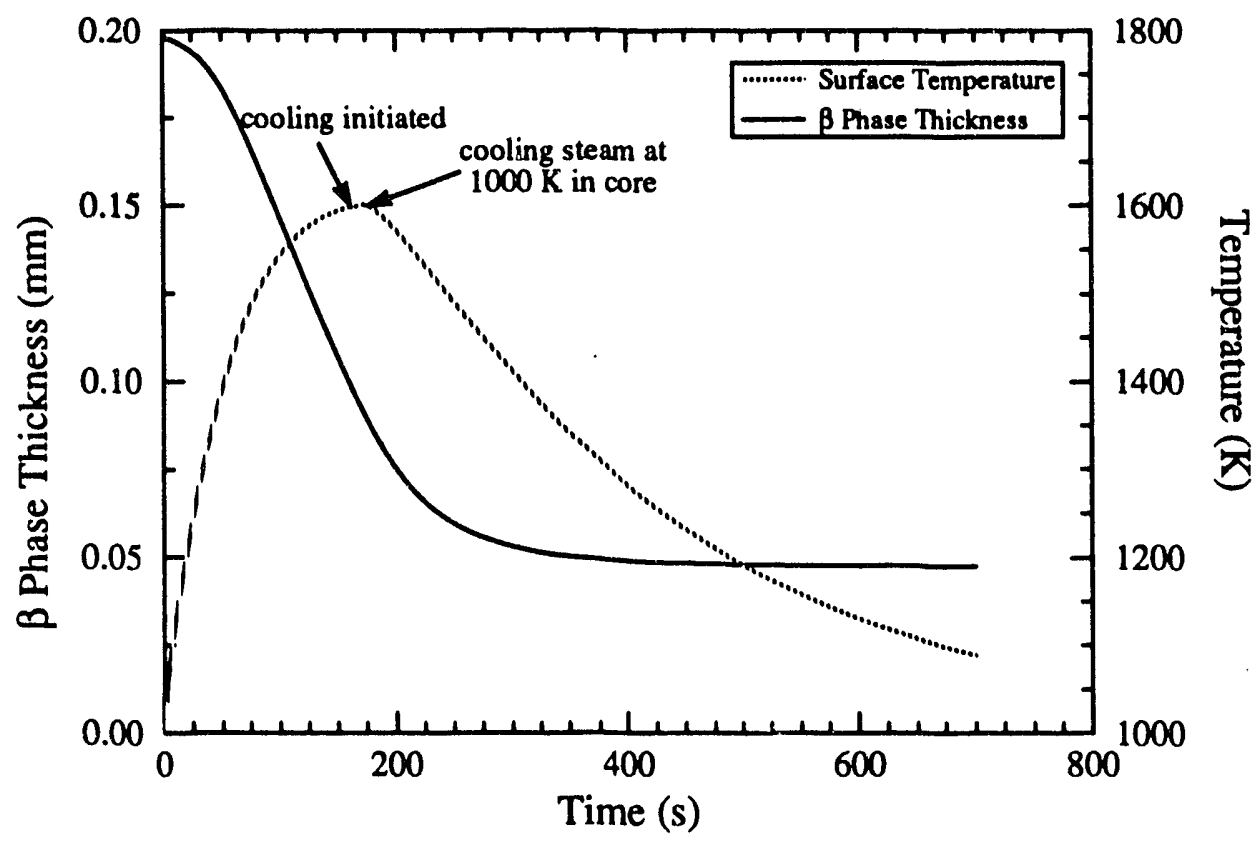

Figure $15 \beta$ phase thickness and surface temperature at axial node one for Case $2 \mathrm{a}$.

Core cooling was initiated at a problem time of 160 seconds when the RELAP trips were met. After initiation of cooling, axial node one continued to heat up until the cooling steam at $1000 \mathrm{~K}$ reached the core at 173 seconds after filling the lower plenum. Within the transition temperature range of $1150 \mathrm{~K}$ to $1560 \mathrm{~K}$, cooling was at an average rate of $1.2 \mathrm{~K} / \mathrm{s}$ and did not cause oxide shattering. The final $\beta$ phase thickness at the end of the problem was $0.048 \mathrm{~mm}$. Table 6 lists the significant events and parameters for Case $2 \mathrm{a}$.

Table 6 Significant events and parameters for Case 2a.

\begin{tabular}{|l|l|}
\hline Maximum core surface temperature prior to cooling & $1598 \mathrm{~K} @ 160 \mathrm{~s}$ \\
\hline Cooling initiation & $160 \mathrm{~s}$ \\
\hline Cooling steam reaches axial node one & $173 \mathrm{~s}$ \\
\hline Average cooling rate in temperature range of $1150 \mathrm{~K}$ to $1560 \mathrm{~K}$ & $1.2 \mathrm{~K} / \mathrm{s}$ \\
\hline Minimum $\beta$ phase thickness & $0.048 \mathrm{~mm}$ \\
\hline
\end{tabular}




\subsection{Test Case 2b}

Test Case $2 \mathrm{~b}$ was run to a successful completion with no $\mathrm{ZrO}_{2}$ shattering. The test problem was to meet criterion 1 only and not cause $\mathrm{ZrO}_{2}$ shattering. The designed parameters were to produce core surface temperatures less than $1150 \mathrm{~K}$, a cooling rate greater than $2 \mathrm{~K} / \mathrm{s}$ and a $\beta$ phase thickness less than $0.1 \mathrm{~mm}$. Figure 16 shows the nodalization of Case $2 \mathrm{~b}$ with the imposed boundary and initial conditions. The fuel rods were heated by superheated steam at $1500 \mathrm{~K}, 15.6 \mathrm{MPa}$, with a velocity of $0.05 \mathrm{~m} / \mathrm{s}$. Cooling was provided by saturated liquid at $15.6 \mathrm{MPa}$, with a velocity of $0.05 \mathrm{~m} / \mathrm{s}$. Cooling initiation started when the maximum core surface temperature exceeded $1145 \mathrm{~K}$. The $\beta$ phase thickness was initialized below the shattering criteria at $0.098 \mathrm{~mm}$, and an initial uniform temperature of $1000 \mathrm{~K}$ was imposed on the fuel rods.

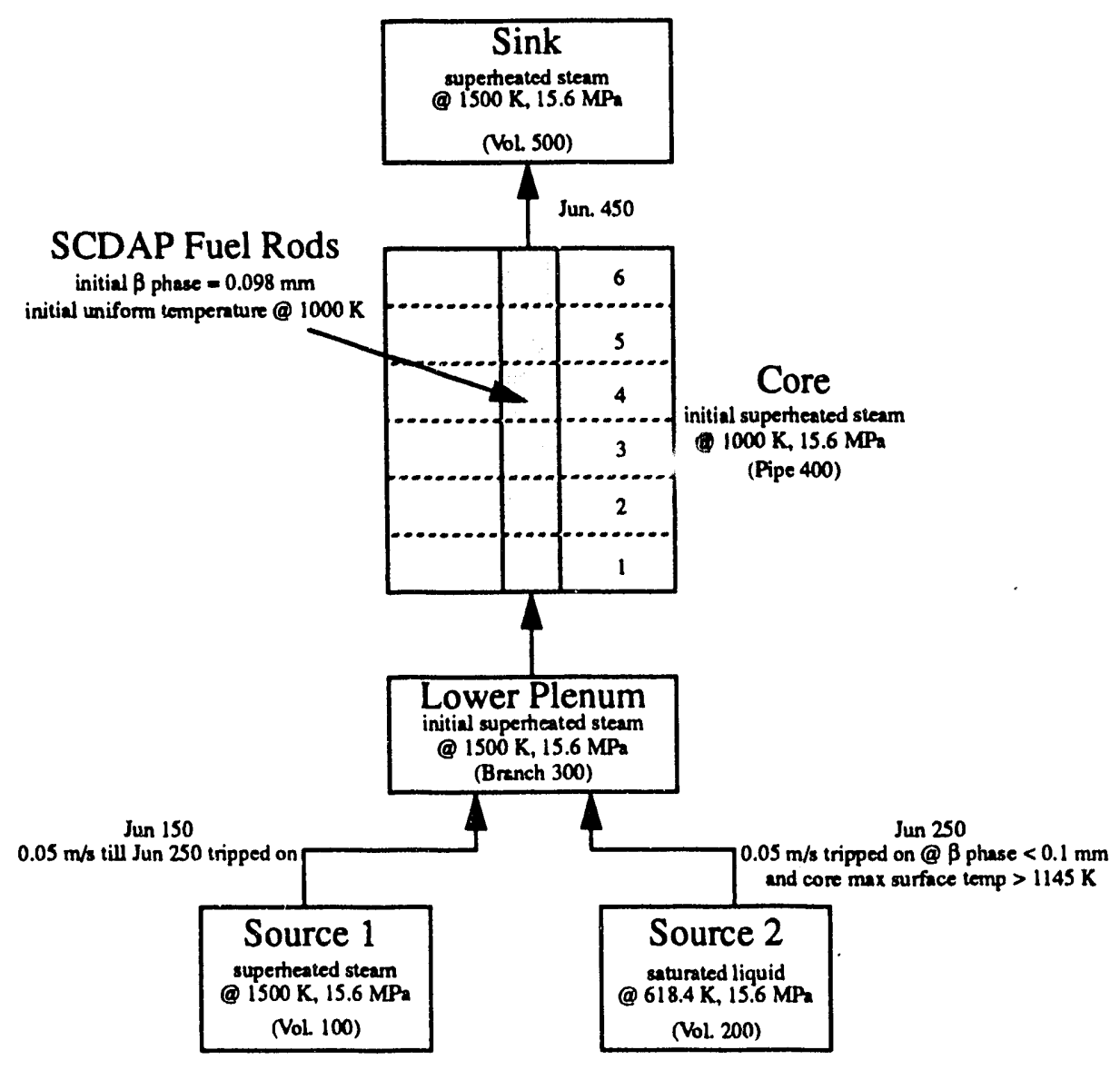

Figure 16 Boundary and initial conditions for Case $2 \mathrm{~b}$.

Figure 17 shows the surface temperature history plot for axial node one. Significant events 
and parameters are listed in Table 7.

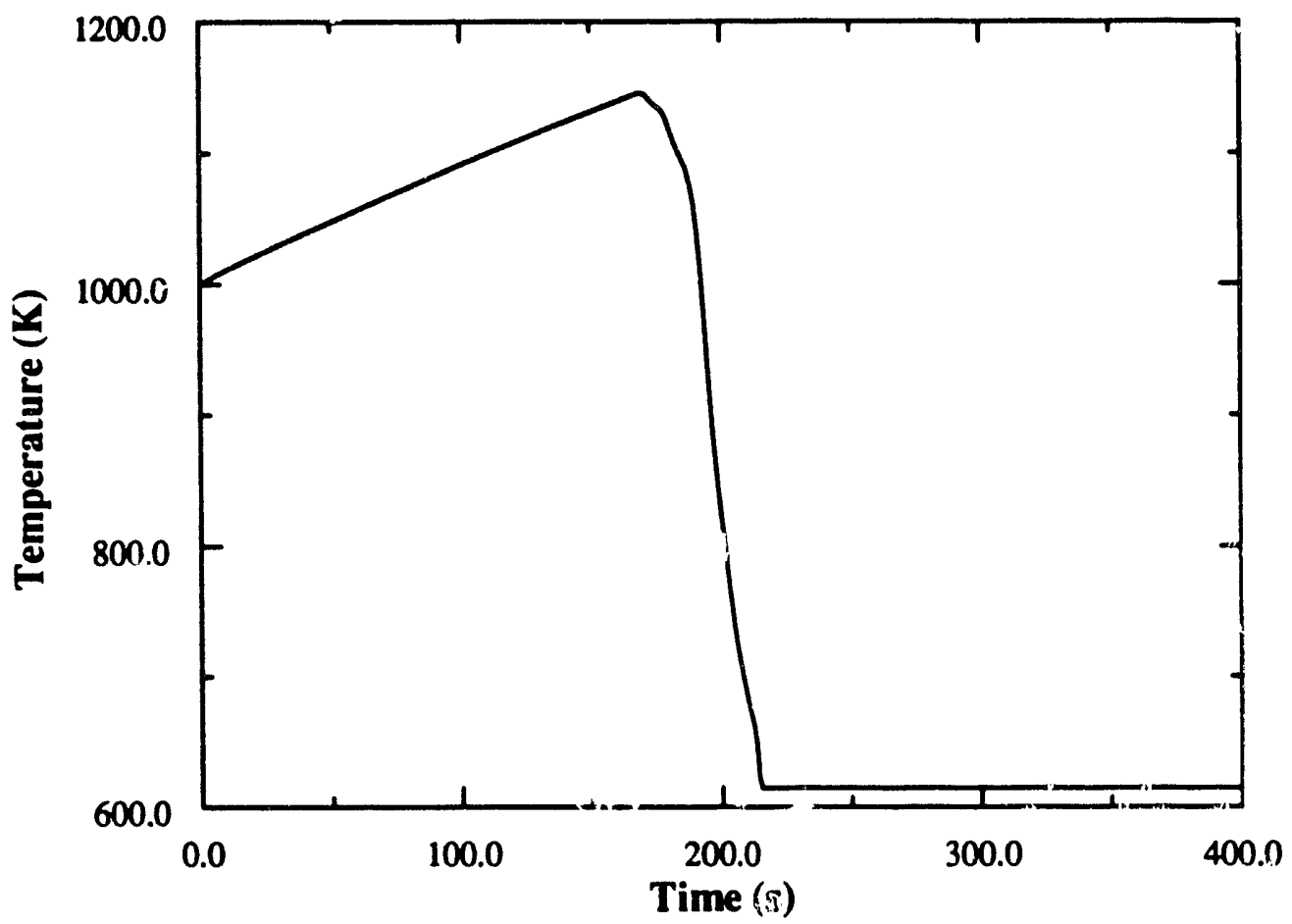

Figure 17 Surface temperature history at axial node one for Case $\mathbf{2 b}$.

At a problem time of 167 seconds, the trip conditionss were met and cooling began. A maximum core surface temperature of $1146 \mathrm{~K}$ was attained two seconds after cooling initiation. The fuel rods were cooled at an average rate of $13 \mathrm{~K} / \mathrm{s}$ to the saturation temperature of $618 \mathrm{~K}$ with no $\mathrm{ZrO}_{2}$ shattering.

Table 7 Significant Events and Parameters for Case $2 b$

\begin{tabular}{|l|l|}
\hline Cooling initiation & $167 \mathrm{~s}$ \\
\hline Maximum core surface temperature & $1146 \mathrm{~K} @ 169 \mathrm{~s}$ \\
\hline End of oxidation at axial node 1 & $194 \mathrm{~s}$ \\
\hline Average cooling rate (range $1146 \mathrm{~K}-618 \mathrm{~K}$ ) & $13 \mathrm{~K} / \mathrm{s}$ @ axial node 1 \\
\hline
\end{tabular}




\subsection{Test Case 3}

Test Case 3 was run to a successful completion with no $\mathrm{ZrO}_{2}$ shattering. The test problem was designed to see core surface temperatures within the temperature range of $1150 \mathrm{~K}$ to $1560 \mathrm{~K}$, a cooling rate greater than $2 \mathrm{~K} / \mathrm{s}$ and a $\beta$ phase thickness greater than $0.1 \mathrm{~mm}$. With these design parameters only criterion 2 was met. Figure 18 shows the nodalization of Case 3 with the imposed boundary and initial conditions.

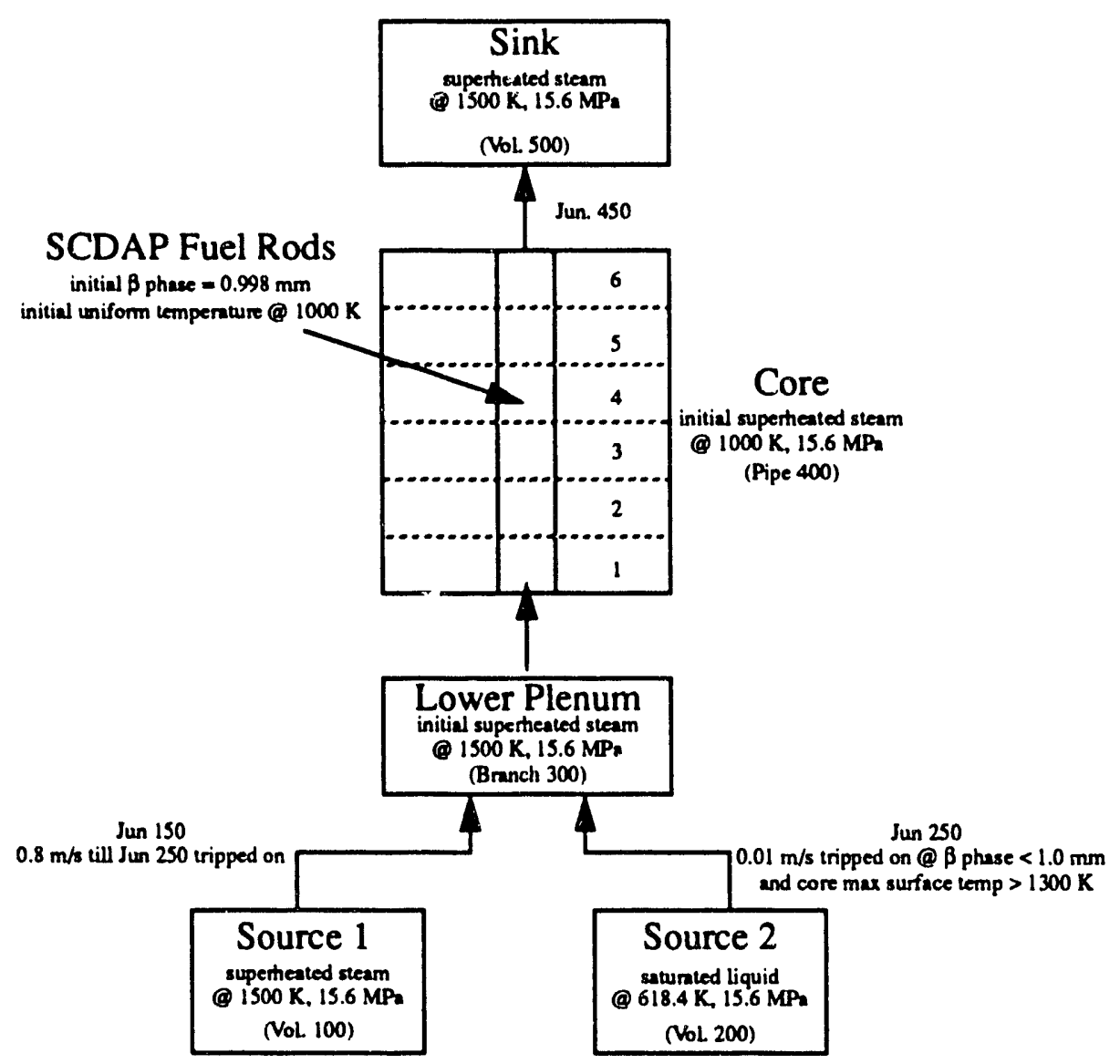

Figure 18 Boundary and initial conditions for Case 3.

The fuel rods were heated with superheated steam at $1500 \mathrm{~K}, 15.6 \mathrm{MPa}$, with a velocity of 0.8 $\mathrm{m} / \mathrm{s}$. Cooling was provided by saturated liquid at $15.6 \mathrm{MPa}$, with a velocity of $0.01 \mathrm{~m} / \mathrm{s}$. Cooling was started when the maximum core surface temperature exceeded $1300 \mathrm{~K}$ and the $\beta$ phase thickness was less than $1 \mathrm{~mm}$. The initial $\beta$ phase th.ckness was $0.998 \mathrm{~mm}$, and an initial uniform temperature of $1000 \mathrm{~K}$ was imposed on the fuel rods. Figure 19 shows the $\beta$ thickness and surface 
temperature time history plot for axial node one.

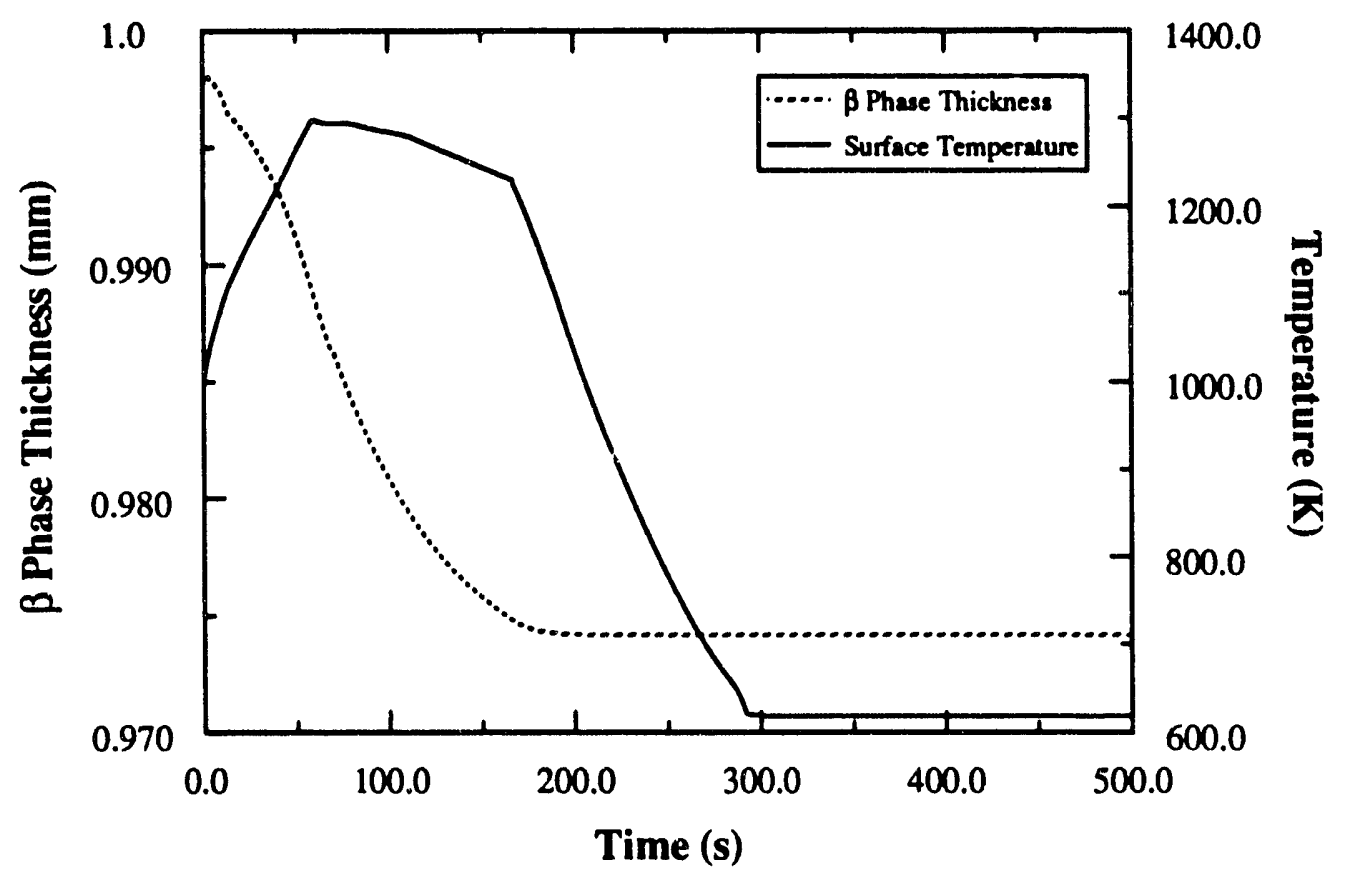

Figure $19 \beta$ phase thickness and surface temperature at axial node one for Case 3.

At a problem time of 59 seconds, the trip conditions were met and cooling began. As shown, the time coincides with the temperature roll-over experienced when junction 150 is tripped off. At a problem time of 167 seconds, saturated liquid began filling axial node one, which is illustrated by the knee in the temperature plot. At a problem time of 196 seconds, oxidation at axial node one stops, which is in agreement with the $\beta$ phase reduction due to oxidation. By a problem time of 300 seconds, axial node one was uneventfully cooled to the saturation temperature of $618 \mathrm{~K}$ without $\mathrm{ZrO}_{2}$ shattering. Significant events and parameters are listed in Table 8. 
Table 8 Significant events and parameters for Case 3.

\begin{tabular}{|l|l|}
\hline Cooling initiation & $59 \mathrm{~s}$ \\
\hline Maximum core surface temperature prior to cooling & $1299 \mathrm{~K} @ 59 \mathrm{~s}$ \\
\hline Saturated liquid in core & $167 \mathrm{~s}$ \\
\hline End of oxidation at axial node one & $196 \mathrm{~s}$ \\
\hline Average cooling rate (range $1150 \mathrm{~K}-1560 \mathrm{~K})$ & $6 \mathrm{~K} / \mathrm{s} @$ axial node 1 \\
\hline Minimum $\beta$ phase thickness for axial node one & $0.97 \mathrm{~mm} @$ axial node 1 \\
\hline
\end{tabular}

\subsection{Conclusion}

Two main conclusions were drawn from the verification process:

- Under the boundary conditions tested, the $\mathrm{ZrO}_{2}$ shattering model increased the severity of core damage calculated by SCDAP/RELAP5.

- The programming logic for initiation of $\mathrm{ZrO}_{2}$ shattering was coded as intended. 


\section{Recommendations}

Based upon the body of work documented in this report, the authors believe they can make several pertinent recommendations. The first regards the validation of the reflood oxidation models incorporated into SCDAP/RELAP5 with this report. The second regards further elimination of the underprediction of hydrogen production now being observed, and the third suggests refinements to the existing model.

The reflood oxidation models documented in this report and incorporated into SCDAP/ RELAP5 have been verified, as documented in Section 5, and should behave as intended. While this verification completes the scope of a design rep ort in that it provides acceptance testing, it does not validate the models. Any analytical model of an event as dynamic as reflood of a potentially damaged reactor core is prone to a relatively large degree of uncertainty, because reflood is difficult to examine experimentally. We therefore recommend that these reflood oxidation models be validated and assessed against several experimentally observed reflood of a damaged core. CORA-13 (International Standard Problem 31) would seem to be an excellent starting point, since it best isolates the reflood phenomena. The reflood of OECD LOFT Experiment LP-FP-2 also seems to provide a unique opportunity for code validation and assessment, which would provide the user community an understanding of the uses and limitations of the new code models.

Zircaloy cladding has been observed to oxidize during relocation and after resolidification during subsequent heatups. PIE of the LOFT LP-FP-2 center fuel module [5] showed oxidized uranium and zirconium in melts that relocated during reflood to form a blockage at the second spacer grid. Metallographic examination of the PBF-SFD 1-3 test indicated that zircaloy continued to oxidize during and following relocation [Ref 9, p. 141]. While current models oxidize material while they remain within intact geometry, no model will currently oxidize relocating debris or debris that has resolidified and is being exposed to additional heating. This seems unnecessarily nonconservative. The authors recommend that oxidation of molten debris, as well as relocated material, be considered.

Finally, the current oxidation models make use a set of parabolic rate equations to model the 
oxidation process. While this has some benefits, particularly in computational time, it would be of benefit to have available a diffusion model to examine oxygen diffusion through $\mathrm{Zr}$ and $\mathrm{ZrO}_{2}$. Such a model would benefit the user in the following manner: (1) the user would no longer have to model $\mathrm{ZrO}_{2}$ failure with a user-input failure temperature, (2) the impact of oxygen content on cladding strength could be modeled, and finally, (3) a refined model of oxidation would be available to the user. Such a diffusion model should not directly replace the existing parabolic rate equation models, since a significant fraction of the user community would not sufficiently benefit from the new model to justify the additional computational time. However, it would be appropriate to offer the user a choice between the two models. 


\section{References}

1 C. Allison and E. Johnson (eds.), SCDAP/RELAP5!MOD3 Code Manual, Volumes 1,2 and 3, NUREG/CR-5273, EGG-2555, September 1990.

2 C. Allison, Coupled Temperature/Oxidation Model for SCDAP/MODO, EGG-CDD5751, January 1982, pg 5.

3 N. Hampton and D. Hagrman, Cladding Oxidation (CORROS, COBILD, COXIDE, COXWTK and COXTHK), EGG-CDD-5647, November 1981, pg. 5.

4 MATPRO - A Library of Materials Properties for Light-Water-Reactor Accident Analysis, NUREG/CR-5273, EGG-2555, Sept. 1989.

5 M. Carboneau, Experimental Analysis and Summary for OECD LOFT Project Fission Product Experiment LP-FP-2, OECD LOFT-T-3806, June 1989.

6 P. Hofmann, Metallographic Examination of the Severe Fuel Damage Scuping Test (SFD-ST) Fuel Rod Bundle Cross Sections_ NUREG/CR-5119, EGG-2537, July 1988.

7 S. Jensen, et al., Postirradiation Examination Data and Analysis for OECD LOFT Fision Product Experiment LP-FP-2, OECD LOFT-T-3810, Vol. 1, December 1989.

8 A. Knipe, et al., PBF Severe Fuel Damage Scoping Test - Test Results Report, NUREG/ CR-4683 EGG-2413, August 1986.

9 Z. Martinson, et al., PBF Severe Fuel Damage Test 1-3 Test Results Report ${ }_{2}$ NUREG/CR - 5354, EGG-2565, October 1989.

10 K. Minato, et. al., Zircaloy Oxidation and Cladding Deformation in PWR-Specific CORA Experiments, KfK 4827, July 1991.

11 D. Kirsch, Investigations on the Flow and Temperature Distribution Downstream of Local Coolant Blockages in Rod Bundle Subassemblies, Nuclear Engineering and Design 31 (1974) pp. 266-279.

12 B.J. Vegter et al., Measurements of Velocities Downstream of Blocked Subchannels in a Model Reactor Rod Bundle, Research Report 74-8E9-RODS-R1, December 30, 1974.

13 M.B. Richards and A.W. Barsell, Parametric Analysis Of The Reaction Of Steam With N Reactor Pressure Tube Zircaloy-2 Surfaces, GA-C18884, June 1987.

14 S. Modro and M. Carboneau, The LP-FP-2 Severe Fuel Damage Scenario and Discussion of the Relative Influence of the Transient and Reflood Phases in Affecting the Final Condition of the Bundle, presented at the OECD LOFT Final Meeting, Madrid, Spain, May 9-11, 1990.

15 H. M. Chung and T. F. Kassner, Embrittlement Criteria for Zircaloy Fuel Cladding Applicable to Accident Situations in Light-Water Reactors: Summary Report, NUREG/ CR-1344, ANL-79-48, January 1980, pp. 23-28 

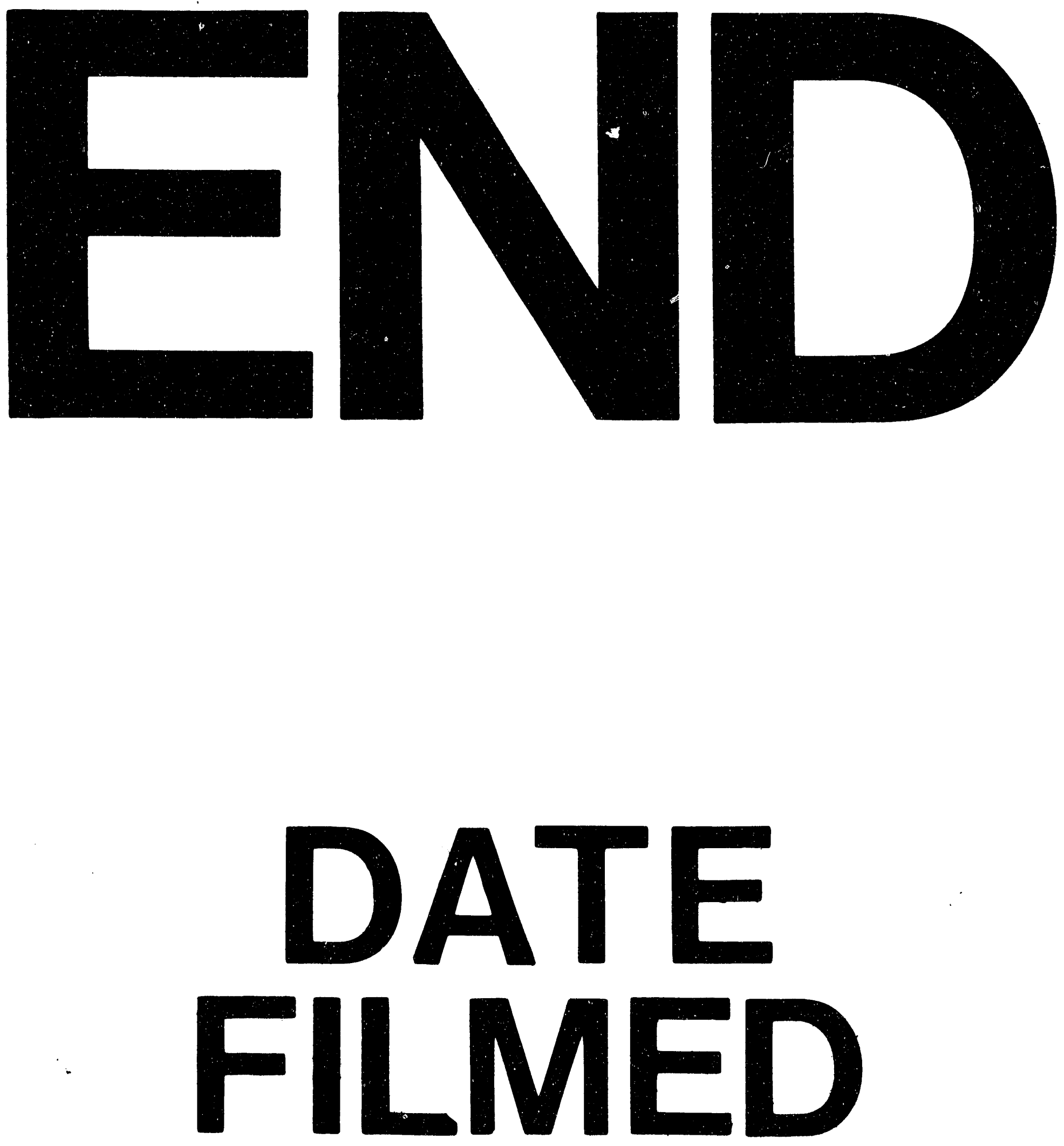

1

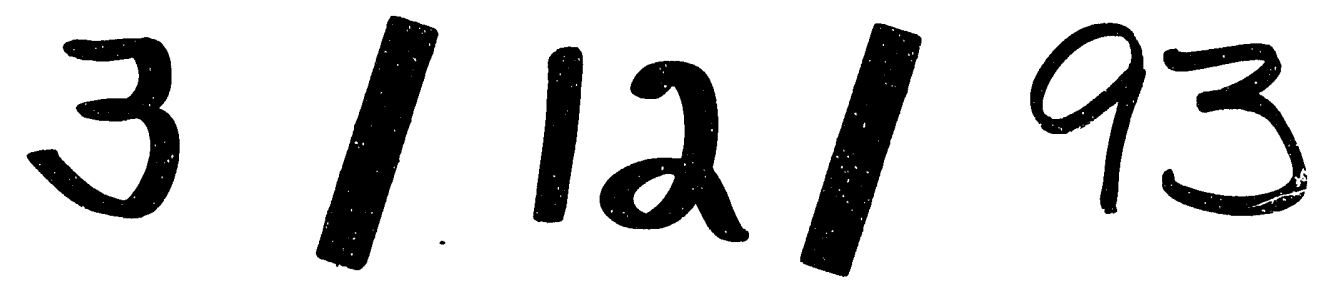


